\title{
Dopamine D2-like receptor stimulation blocks negative feedback in visual and spatial reversal learning in the rat: behavioural and computational evidence
}

\author{
Johan Alsiö ${ }^{1}$ (D) Benjamin U. Phillips ${ }^{1,2} \cdot$ Júlia Sala-Bayo $^{1}$ - Simon R. O. Nilsson ${ }^{1,3,4} \cdot$ Teresa C. Calafat-Pla $^{1}$ • \\ Arazo Rizwand ${ }^{1}$ • Jessica M. Plumbridge ${ }^{1}$ - Laura López-Cruz ${ }^{1}$ - Jeffrey W. Dalley ${ }^{1,5}$ • Rudolf N. Cardinal ${ }^{1,5,6}$. \\ Adam C. Mar ${ }^{1,3,4}$. Trevor W. Robbins ${ }^{1}$
}

Received: 14 February 2019 / Accepted: 2 June 2019 / Published online: 19 June 2019

(C) The Author(s) 2019

\begin{abstract}
Rationale Dopamine D2-like receptors (D2R) are important drug targets in schizophrenia and Parkinson's disease, but D2R ligands also cause cognitive inflexibility such as poor reversal learning. The specific role of D2R in reversal learning remains unclear.

Objectives We tested the hypotheses that D2R agonism impairs reversal learning by blocking negative feedback and that antagonism of D1-like receptors (D1R) impairs learning from positive feedback.

Methods Male Lister Hooded rats were trained on a novel visual reversal learning task. Performance on "probe trials", during which the correct or incorrect stimulus was presented with a third, probabilistically rewarded (50\% of trials) and therefore intermediate stimulus, revealed individual learning curves for the processes of positive and negative feedback. The effects of D2R and D1R agonists and antagonists were evaluated. A separate cohort was tested on a spatial probabilistic reversal learning (PRL) task after D2R agonism. Computational reinforcement learning modelling was applied to choice data from the PRL task to evaluate the contribution of latent factors.

Results D2R agonism with quinpirole dose-dependently impaired both visual reversal and PRL. Analysis of the probe trials on the visual task revealed a complete blockade of learning from negative feedback at the $0.25 \mathrm{mg} / \mathrm{kg}$ dose, while learning from positive feedback was intact. Estimated parameters from the model that best described the PRL choice data revealed a steep and selective decrease in learning rate from losses. D1R antagonism had a transient effect on the positive probe trials.

Conclusions D2R stimulation impairs reversal learning by blocking the impact of negative feedback.
\end{abstract}

Keywords Dopamine · Cognition · Dopamine D2 receptor · Rat · Dopamine D1 receptor · Reversal learning · Cognitive flexibility $\cdot$ Computational modelling $\cdot$ Hierarchical Bayesian analysis $\cdot$ Reinforcement learning

This article belongs to a Special Issue on Translational Computational Psychopharmacology

Electronic supplementary material The online version of this article (https://doi.org/10.1007/s00213-019-05296-y) contains supplementary material, which is available to authorized users.

Johan Alsiö

ja476@cam.ac.uk

1 Department of Psychology and Behavioural and Clinical Neuroscience Institute, University of Cambridge, Cambridge, UK

2 Department of Physiology, Development and Neuroscience, University of Cambridge, Cambridge, UK
3 Neuroscience Institute, New York University Medical Center, New York, NY, USA

4 Department of Neuroscience and Physiology, School of Medicine, New York University, New York, NY, USA

5 Department of Psychiatry, University of Cambridge, Cambridge, UK

6 Cambridgeshire \& Peterborough NHS Foundation Trust, Box 190 (Liaison Psychiatry), Cambridge Biomedical Campus, Cambridge, UK 


\section{Introduction}

Cognitive flexibility is required to navigate in a changing environment and requires both new associative learning and the ability to disregard rules when they become obsolete. Impairments in neuropsychological tests designed to measure such flexibility, e.g. reversal learning, are observed in psychiatric and neurological disorders including schizophrenia (Leeson et al. 2009) and Parkinson's disease (PD; (Cools et al. 2007)). Despite this, current drug treatments often fail to remediate cognitive impairment in schizophrenia (e.g. (Leeson et al. 2009)); in the case of PD, the same drugs that restore voluntary movement by increasing dopamine (DA) tone in the dorsal striatum may even contribute to impairments in reversal learning, perhaps by "overdosing" the relatively intact ventral striatum with DA or DA D2-like receptor (D2R) agonists (Swainson et al. 2000).

Electrophysiological experiments in animals have shown that, in healthy individuals, the activity of DA neurons correlates reliably with a theoretical reward prediction error: firing rates increase in response to unexpected reward and decrease after unexpected reward omission (Schultz 2013). The causal link between this neuronal activity and reinforcement learning has been demonstrated using optogenetic approaches in rats, from the perspectives of both positive (Steinberg et al. 2013) and negative prediction errors (Chang et al. 2016). In agreement with these studies, DA activity also provides a prediction error signal during reversal learning, transiently declining in response to errors after a shift in response-outcome contingencies and increasing after unexpected rewards, as the subjects begin to interact with the previously non-rewarded, now rewarded response option (Klanker et al. 2015; Verharen et al. 2018).

At the level of the striatum, which receives the majority of midbrain DA output, D2R and D1-like receptors (D1R) are segregated between striatopallidal (indirect-pathway) and striatonigral (direct-pathway) neurons, respectively (Gerfen et al. 1990). Since D1R stimulate and D2R inhibit cAMP production, striatonigral neurons are predicted to increase cAMP and downstream signalling in response to positive prediction errors when dopamine levels transiently increase, whereas striatopallidal neurons instead respond more to negative prediction errors when dopamine levels decrease (Yapo et al. 2017). In seminal work by Frank and colleagues, reinforcement learning was altered in PD patients only after they had taken their dopaminergic medication (Frank et al. 2004): there was a selective reduction in learning from losses in a probabilistic selection task (PST), in which subjects solved two-choice visual discrimination problems either by learning to approach the positive stimuli or by learning to avoid the negative stimuli (Frank et al. 2004). A proposed explanation was that supraphysiological levels of DA block learning from negative feedback by rendering $\mathrm{D} 2 \mathrm{R}$-expressing striatopallidal neurons indifferent to dips in dopamine (which would impair learning from negative feedback). Hypodopaminergic states, in contrast, would not allow D1Rexpressing striatonigral cells to detect DA burst firing (which would impair learning from positive feedback) (Cox et al. 2015; Frank et al. 2004). Supporting this account, variation in the $D R D 2$ gene was linked to learning from losses in the PST task, whereas a polymorphism in the DARPP32 gene, intimately linked to D1R function (Calabresi et al. 2000), instead predicted learning from wins (Frank et al. 2007). Imaging experiments additionally revealed that D1R and D2R radioligand binding correlates with learning from positive and negative feedback, respectively (Cox et al. 2015). Further support for this view comes from the observation that mice lever-press for optogenetic stimulation of striatonigral neurons, whereas they avoid a lever linked to optogenetic stimulation of striatopallidal neurons (Kravitz et al. 2012). Whereas pharmacological evidence for this model of the basal ganglia is still lacking, D2Rs have been heavily implicated in reversal learning in humans (Clatworthy et al. 2009; Mehta et al. 2001), non-human primates (Groman et al. 2011; Horst et al. 2019; Lee et al. 2007), rats (Boulougouris et al. 2009) and mice (Laughlin et al. 2011; Linden et al. 2018). The evidence for D1R involvement in reversal learning, in contrast, is equivocal; e.g., systemic treatment with a D1R agonist in mice only transiently impaired visual reversal learning (Izquierdo et al. 2006), and D1R antagonism in vervet monkeys did not significantly affect reversal learning in an object reversal learning task sensitive to D2R agents (Lee et al. 2007).

To investigate the specific roles for D1R and D2R in reversal learning further, and based on recent advances in cognitive tasks for rats and mice (Markou et al. 2013; Nilsson et al. 2015; Phillips et al. 2018), we established a novel touchscreen reversal-learning paradigm for rats, in which standard two-choice visual discrimination trials (CS+ vs. CS-) were interleaved with "probe" trials, where a stimulus of intermediate valence $\left(\mathrm{C}_{50 / 50}\right)$ was presented with either the CS+ or CS-. Assuming that the intermediate value of the $\mathrm{C}_{50 / 50}$ is known (by means of pre-training), subjects' preference for the CS+ over the $\mathrm{C}_{50 / 50}$ reflects their learning from positive feedback on the standard trials, whereas negative feedback should promote a preference for the $\mathrm{C}_{50 / 50}$ over the CS- . We hypothesised that D1R antagonism would cause subjects to pay less attention to positive outcomes and thus fail to prefer the CS+ over the $\mathrm{C}_{50 / 50}$ during reversal learning, whereas subjects would become indifferent to negative feedback after D2R agonism, and hence not discriminate between the CS- and $\mathrm{C}_{50 / 50}$. A number of reference manipulations were tested, including the effect of D2R activation on computationally derived latent variables guiding behaviour in a separate group of rats tested in a serial spatial probabilistic reversal task (Bari et al. 2010). 


\section{Materials and methods}

\section{Compliance with ethical standards}

This research has been regulated under the Animals (Scientific Procedures) Act 1986 Amendment Regulations 2012 (Project licence 70/7548) following ethical review by the University of Cambridge Animal Welfare and Ethical Review Body (AWERB).

\section{Subjects}

Male Lister Hooded rats (Charles River, Kent, UK) were allowed to acclimatise to the animal facility under a $12 \mathrm{~h}: 12 \mathrm{~h}$ light cycle (lights off at $7 \mathrm{AM}$ ) for a minimum of 7 days before any procedures began. Rats were housed in groups of 4 on wood-chip bedding in standard cages with cardboard tunnels as enrichment. When rats reached a body weight of approximately $300 \mathrm{~g}$, they were food-restricted to maintain approximately $90 \%$ of their free-feeding weight trajectory (17.5-19 g of Purina rodent chow per animal and day; adjusted for reward pellet consumption during testing). Water was available ad libitum in the home cage. The experiments used a total of 124 rats (for details, see Table 1).

\section{Drugs}

All drugs were dissolved in saline and injected via the intraperitoneal route. Raclopride (Tocris Bioscience, Bristol, UK) was administered at $0,0.015,0.03$, and $0.06 \mathrm{mg} / \mathrm{kg}, 20 \mathrm{~min}$ before testing. SCH39166 hydrobromide (Tocris Bioscience) was administered at $0,0.025,0.05$, and $0.1 \mathrm{mg} / \mathrm{kg}, 20 \mathrm{~min}$ before testing. Note that SCH39166 was chosen for D1R antagonism to avoid off-target effects at the serotonin $5-\mathrm{HT}_{2 \mathrm{C}}$ receptor, since activity at this receptor affects visual reversal learning (Alsiö et al. 2015). SKF81297 hydrobromide (Tocris Bioscience) was administered at $0,0.1$, and $0.25 \mathrm{mg} / \mathrm{kg}$, 30 min before testing. (-)-Quinpirole hydrochloride (SigmaAldrich, St. Louis, MO, USA) was administered at 0, 0.01, $0.025,0.1,0.25$, and $0.5 \mathrm{mg} / \mathrm{kg}, 60 \mathrm{~min}$ before testing. A broad dose range of quinpirole was chosen to allow detection of potential differential effects of canonical presynaptic and postsynaptic doses (Eilam and Szechtman 1989). No adverse reactions to repeated injections were observed in any experiments.

\section{Visual discrimination and reversal}

\section{Behavioural apparatus}

Food-restricted rats were tested in 16 operant chambers (Med Associates, Georgia, VT, USA; $30 \mathrm{~cm} \times 39 \mathrm{~cm} \times 29 \mathrm{~cm}$ ) placed in sound-attenuating MDF boxes with fans for the purpose of ventilation and masking external noise. A food receptacle centrally placed in one wall of the chamber was connected to an external pellet dispenser delivering $45 \mathrm{mg}$ sucrose pellet (TestDiet 5TUL). A house light was located near the ceiling directly above the magazine. The wall opposite to the food receptacle was replaced by a touchscreen (Elo Touch Solutions, Inc). The chambers were controlled by inhouse software (Visual Basic 2010 Express.NET, Microsoft 2010; developed by A.C.M.).

\section{Pre-training}

Initial touchscreen training is described in detail elsewhere (Alsiö et al. 2015); see Supplementary Table 1 for an overview. Rats were tested once daily, 5-6 days a week, throughout the experiments. Briefly, the rats were first trained to touch a large white rectangular stimulus on the screen for a sugar reward, until receiving 100 rewards within $60 \mathrm{~min}$. A 5-s intertrial interval was employed throughout all procedures. Next, the animals were required to press a medium-sized rectangle and finally a small $(3 \times 4 \mathrm{~cm})$ "start box", located at the bottom centre of the touchscreen. The criterion for moving on from each stage was reaching 100 responses/rewards within $60 \mathrm{~min}$. During the next phase of training, pressing the start box, instead of providing pellets, lead to the presentation of a single visual stimulus on the touchscreen ("Horizontal" or "Vertical"; counterbalanced across rats and alternating between days), randomly presented left or right on the screen. Touching the stimulus lead to reward delivery whereas pressing the no-stimulus (black) side lead to a 5-s timeout, during which the house light was turned on. In order to prevent accidental contact with the screen, while at the same time promoting quick progress in the training, the stimulus was presented further down on the screen for the first sessions but moved up to approximately $7 \mathrm{~cm}$ height once the rat had reached $>80 \%$ correct (out of 100 trials) across 2 days. When the rat had reached $>80 \%$ on two consecutive sessions with the higher stimulus position, pre-training was complete.

\section{Touchscreen visual discrimination and reversal}

During the next stage of training, trials were initiated by pressing the start box as above, but rats were required to discriminate between two stimuli presented simultaneously on the screen (CS+ vs. CS-; "Horizontal" or "Vertical"; counterbalanced across rats). The animals were tested until the session they reached the running learning criterion of 24 correct in 30 trials at least once during a session (reaching criterion did not terminate the session). This visual discrimination phase normally required 1-3 days of training. A retention session was included the day after rats initially reached criterion. In addition, another retention session was then included before the stimulus-outcome contingencies were 
Table 1 Experimental cohorts and stimuli used in the visual tasks

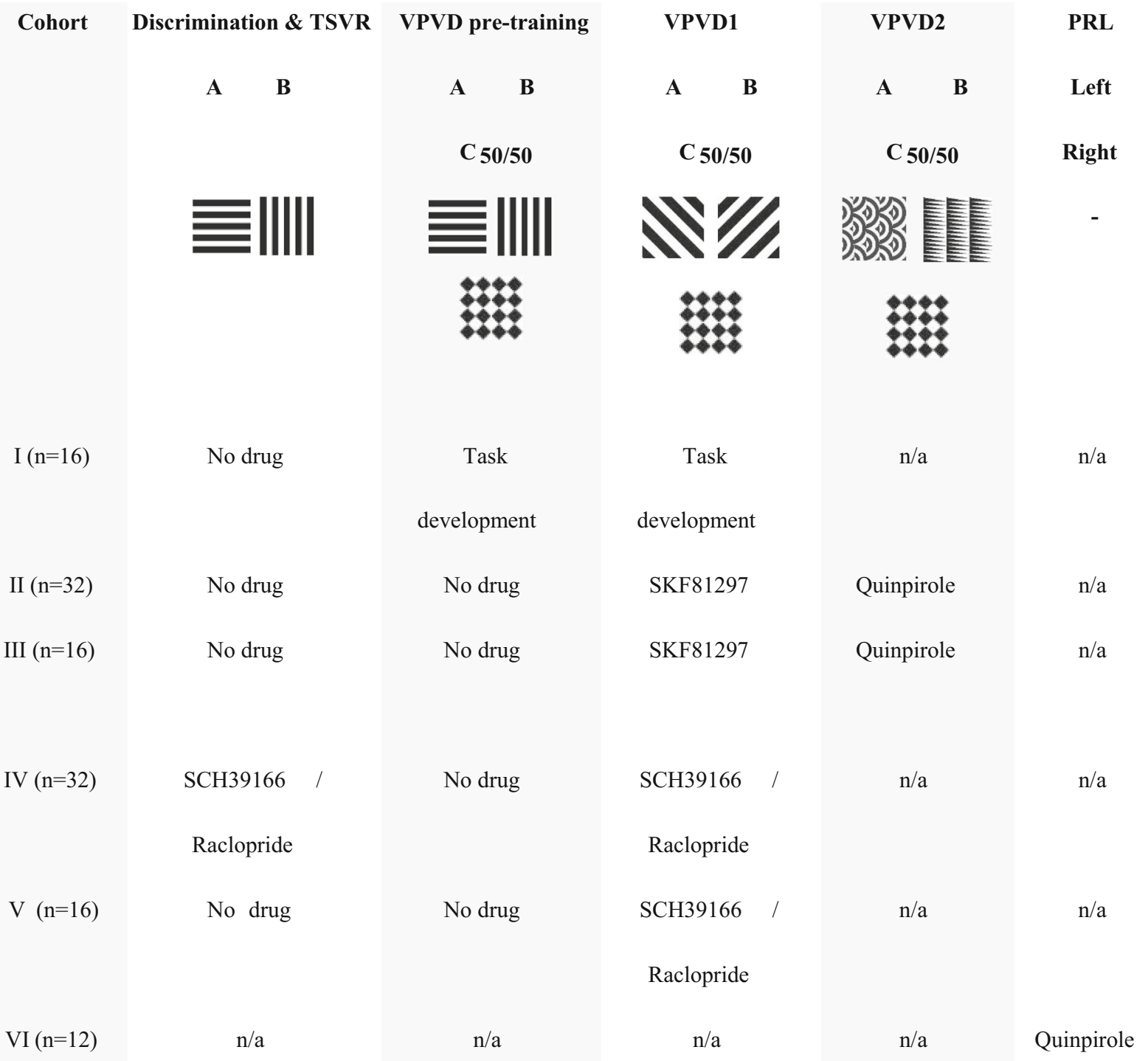

Stimulus-outcome contingencies were counterbalanced across drug groups. A different probe stimulus $\left(\mathrm{C}_{50 / 50}\right)$ exemplar was tested in some rats in the task development experiment (not shown). TSVR, touchscreen serial visual reversal task; VPVD, valence-probe visual discrimination task; $P R L$, probabilistic reversal learning task (spatial)

reversed. Rats were then trained on the reversed conditions until they reached the same criterion (24/30); this normally required 4-8 days of training. A single retention session was again included after rats reached criterion on reversal. See Electronic Supplementary Material for a description of the serial reversal learning task (cohort IV; cf. Table 1).

\section{Valence-probe visual discrimination task with reversal}

After the pre-training reversal was completed, the rats progressed to the valence-probe visual discrimination (VPVD) task. Here, the trial structure was kept constant but a tone was played every time a trial was rewarded and the stimulus duration was unlimited, meaning no omissions could occur. In addition, a third stimulus, probabilistically rewarded on average $50 \%$ of the time and therefore termed $\mathrm{C}_{50 / 50}$, was paired with either the $\mathrm{CS}+$ or CS- on "probe" trials (Fig. 1). Initially (Experiment 1), 16 rats were trained on the VPVD reversal task (see method, below) to compare the impact of different probe stimuli ("Diamonds" and "Rings") and frequency of probe-trial presentations (every 4 or 5 trials). For each condition, $n=4$. Rats trained with the "Diamonds" stimulus and an average probe-trial frequency of 


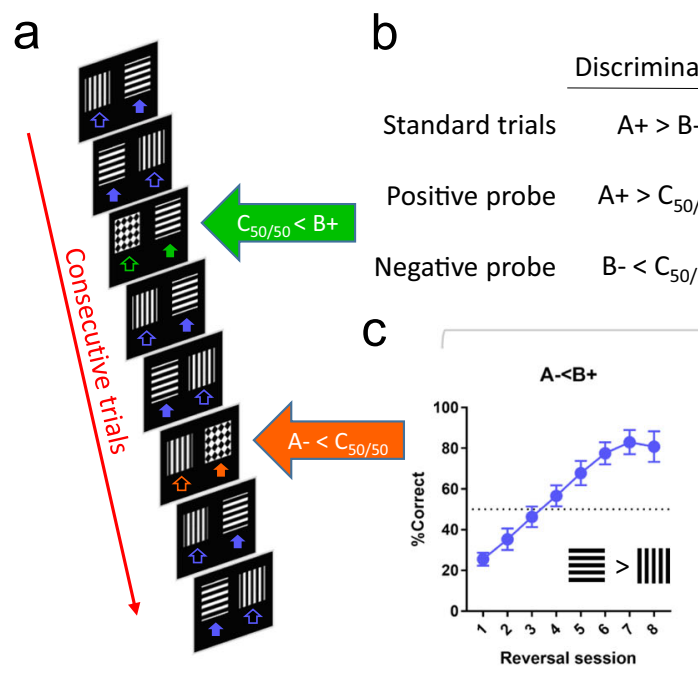

Fig. 1 Trial structure and learning curves for the three trial types in the valence-probe visual discrimination (VPVD) reversal task. a Example trial sequence. $\mathbf{b}$ Regular two-choice trials during both visual discrimination $(\mathrm{A}+>\mathrm{B}-)$ and subsequent reversal learning $(\mathrm{A}-<\mathrm{B}+)$ are interleaved with "probe" trials. During such trials, a third stimulus that is probabilistically linked to reward (50/50\% chance of reward/no reward; $\mathrm{C}_{50 / 50}$ ) is presented with either the positive or the negative stimulus. c) Rats are below chance on the first day of reversal on all three trial types,

every 4 trials (see Fig. 1a, b) displayed better performance on both visual discrimination and on reversal than other combinations (data not shown).

After optimisation, the probe stimulus was set to "Diamonds" and each of the probe trials $\left(\mathrm{CS}+\right.$ vs. $\mathrm{C}_{50 / 50}$ or $\mathrm{C}_{50 / 50}$ vs. $\mathrm{CS}-$ ) was presented once every 8 trials; randomised but never on the first trial within any 8 -trial bin. The rats received a maximum of 200 trials per session (i.e. 150 standard trials CS+ vs. CS-; 25 trials $\mathrm{CS}+$ vs. $\mathrm{C}_{50 / 50} ; 25$ trials of $\mathrm{C}_{50 / 50}$ vs. $\mathrm{CS}^{-}$). As during pretraining, both the inter-trial interval and the timeout (on nonrewarded trials) was $5 \mathrm{~s}$. No omissions were allowed in the VPVD task, in order to ensure that the rats completed the probe trials. See Supplementary Fig. 1 for a comparison of the trial structure in the different behavioural tasks.

Rats were initially tested for 5 days on the same CS+ and $\mathrm{CS}-$ as during the pre-training reversal above (i.e. "Horizontal" vs. "Vertical"). The animals then completed a visual discrimination with a novel pair of stimuli ("Slash" vs. "Backslash"; counterbalanced across rats; $\mathrm{CS}+$ and $\mathrm{CS}-$ is here referred to as $\mathrm{A}+$ and $\mathrm{B}-$ during visual discrimination). Training continued for a minimum of 5 sessions, but was extended for any rat to allow them to reach $80 \%$ correct on the standard $\left(\mathrm{A}+>\mathrm{B}^{-}\right)$trials within the task. Next, the rats received a vehicle (saline) injection and were given a retention test session (on rare occasions, rats were given a second retention session with saline injection to achieve the $80 \%$ inclusion criterion). On the next day, rats were matched for stimulus-reward contingencies, performance on the probe trials before reversal and pre-training reversal performance, and randomly allocated to a drug group according to the experiment (Table 1). The stimulus-reward contingencies were reversed before the session and testing on the reversal phase continued for 10-14 days. The drug corresponding to each rat was administered before testing each day. Note that during reversal, the $\mathrm{CS}+$ and $\mathrm{CS}-$ are referred to as $\mathrm{B}+$ and $\mathrm{A}-$, respectively. Note also that the same stimulus exemplar (i.e. "Diamonds") was used as the probe stimulus for all rats and across each of the phases: pre-training on the VPVD task, initial visual discrimination and during the reversal phase.

As shown in Table 1, the same cohorts (II and III) received both SKF81297 and subsequently quinpirole; training during the quinpirole experiment followed the same procedure as above but rats were trained up on a new pair of stimuli ("Arcs" vs. "Triangles"; counterbalanced across rats; note that the probestimulus exemplar, i.e. "Diamonds", was kept the same also throughout the second visual discrimination and reversal phase) before reversal of the new stimulus-reward contingencies (CS+ and $\mathrm{CS}-$ is referred to as $\mathrm{B}+$ and $\mathrm{A}-$ during reversal). In this case, the allocation into drug groups was also balanced based on previous drug exposure. It should also be noted that the SCH39166 and raclopride cohort had been trained on a high number of serial reversals before being tested on the VPVD task (Table 1; see Electronic Supplementary Material).

\section{Statistical analysis of data from the VPVD task}

On the VPVD reversal task, main measures were percentage correct responses (\%Correct) on the standard $\mathrm{A}-<\mathrm{B}+$ trials 
and performance on the probe trials across sessions (number of trials where the highest reward-probability option was chosen, i.e. $\mathrm{B}+$ on $\mathrm{B}+>\mathrm{C} 50 / 50$ trials and $\mathrm{C} 50 / 50$ on $\mathrm{A}-<\mathrm{C} 50 /$ 50 trials; \%Optimal choice). These scores were arcsinetransformed for statistical analyses, but are presented as nontransformed values in the figures. \%Correct was analysed with a mixed-model ANOVA with Dose (3-6 levels) and Sessions (10 or 14 levels) as between- and within-subject factors, respectively. \%Optimal choice was analysed in a mixed-model ANOVA with Dose (3-6 levels) as a between-subjects factor and Trial Type (2 levels) and Sessions (10 or 14 levels) as within-subject factors. Behaviour on the probe trials was then analysed further with two-way ANOVA for positive (B+ vs. $\mathrm{C}_{50 / 50}$ ) and negative probes (C- vs. $\mathrm{C}_{50 / 50}$ ), separately.

Data from the standard $(\mathrm{A}-<\mathrm{B}+)$ trials were also divided into separate phases depending on the performance of rats during running blocks of 30 trials (Alsiö et al. 2015). Only data up to (and including) the first block of 30 trials where a rat reached criterion (24 correct) were analysed. Trials were divided into "Early", in which the rats had less than 11 corrects in a running block of 30 trials, and "Late" if the rats scored higher than 19 correct in any block of 30 trials; all other trials were treated as "Mid". The number of errors in each phase was calculated and square-root transformed. Repeated-measures ANOVA were then performed with two within-subject factors: phase (3 levels) and dose (4 levels). We also analysed performance on the first reversal session (Alsiö et al. 2015; Izquierdo et al. 2006). Auxiliary measures were latencies to respond to the different stimuli and latencies to collect reward (log-transformed from latencies in milliseconds and averaged across sessions; Table 2 shows the corresponding average latencies in milliseconds). For repeatedmeasures variables, the Greenhouse-Geisser correction was employed when prompted by significant Mauchly's tests of sphericity. Testing of two rats was aborted and their data excluded due to computer malfunction (quinpirole $0.25 \mathrm{mg} / \mathrm{kg}, n=1$; raclopride $0.03 \mathrm{mg} / \mathrm{kg}, n=1$ ).

\section{Serial spatial probabilistic reversal task}

\section{Apparatus}

Testing took place in Campden Instruments ("Bussey-Saksida") touchscreen chambers controlled by ABETII (Lafayette Instruments) and Whisker control software (Cardinal and Aitken 2010). The chambers were housed inside fibreboard boxes with fans for ventilation and to exclude noise. They were equipped with touchscreen monitors, tone generators, LED house lights and a magazine unit with light and infrared beam to detect head entries (opposite side to the touchscreen); a pellet dispenser delivered 45-mg sucrose pellets (TestDiet 5TUL). The chambers had a trapezoidal shape to guide the rats' attention to the screen and food receptacle. We used a 5-hole "mask" to seal off most of the touchscreen; positions 2 and 4 were used throughout testing.
Table 2 Latencies to respond at the screen and to collect sucrose pellets on rewarded trials

\begin{tabular}{|c|c|c|}
\hline Experiment & Response latency (ms) & Collection latency (ms) \\
\hline \multicolumn{3}{|l|}{ Expt. 2 (VPVD) } \\
\hline \multicolumn{3}{|l|}{ Quinpirole } \\
\hline Vehicle & $1066 \pm 38$ & $1529 \pm 50$ \\
\hline $0.01 \mathrm{mg} / \mathrm{kg}$ & $1231 \pm 76$ & $1786 \pm 114$ \\
\hline $0.025 \mathrm{mg} / \mathrm{kg}$ & $1261 \pm 119$ & $1916 \pm 133 *$ \\
\hline $0.1 \mathrm{mg} / \mathrm{kg}$ & $1179 \pm 59$ & $2257 \pm 104 * * *$ \\
\hline $0.25 \mathrm{mg} / \mathrm{kg}$ & $1183 \pm 126$ & $2559 \pm 118^{* * *}$ \\
\hline $0.5 \mathrm{mg} / \mathrm{kg}$ & $1213 \pm 93$ & $2556 \pm 102 * * *$ \\
\hline \multicolumn{3}{|l|}{ Expt. 3 (VPVD) } \\
\hline \multicolumn{3}{|l|}{ SKF81297 } \\
\hline Vehicle & $1122 \pm 65$ & $1379 \pm 45$ \\
\hline $0.1 \mathrm{mg} / \mathrm{kg}$ & $1279 \pm 98$ & $1436 \pm 50$ \\
\hline $0.25 \mathrm{mg} / \mathrm{kg}$ & $1064 \pm 74$ & $1612 \pm 70^{* *}$ \\
\hline \multicolumn{3}{|l|}{ Expt. 4 (TSVR) } \\
\hline \multicolumn{3}{|l|}{ SCH39166 } \\
\hline Vehicle & $1061 \pm 71$ & $970 \pm 61$ \\
\hline $0.025 \mathrm{mg} / \mathrm{kg}$ & $1137 \pm 69$ & $1126 \pm 68$ \\
\hline $0.05 \mathrm{mg} / \mathrm{kg}$ & $1167 \pm 72$ & $1227 \pm 106$ \\
\hline $0.1 \mathrm{mg} / \mathrm{kg}$ & $1190 \pm 69^{*}$ & $1438 \pm 122 *$ \\
\hline \multicolumn{3}{|l|}{ Raclopride } \\
\hline Vehicle & $1247 \pm 91$ & $968 \pm 73$ \\
\hline $0.015 \mathrm{mg} / \mathrm{kg}$ & $1171 \pm 78$ & $1013 \pm 68$ \\
\hline $0.03 \mathrm{mg} / \mathrm{kg}$ & $1300 \pm 119$ & $1168 \pm 98 *$ \\
\hline $0.06 \mathrm{mg} / \mathrm{kg}$ & $1386 \pm 118^{*}$ & $1392 \pm 134 *$ \\
\hline \multicolumn{3}{|l|}{ Expt. 4 (VPVD) } \\
\hline Vehicle & $1047 \pm 39$ & $1344 \pm 45$ \\
\hline SCH39166 (0.05) & $1209 \pm 72$ & $1508 \pm 76$ \\
\hline Raclopride (0.03) & $1094 \pm 66$ & $1424 \pm 41$ \\
\hline \multicolumn{3}{|l|}{ Expt. 5 (PRL) } \\
\hline \multicolumn{3}{|l|}{ Quinpirole } \\
\hline Vehicle & $1155 \pm 179$ & $1706 \pm 72$ \\
\hline $0.025 \mathrm{mg} / \mathrm{kg}$ & $2810 \pm 467 * * *$ & $2038 \pm 94 * *$ \\
\hline $0.1 \mathrm{mg} / \mathrm{kg}$ & $4608 \pm 639 * *$ & $3478 \pm 905^{*}$ \\
\hline $0.25 \mathrm{mg} / \mathrm{kg}$ & $5321 \pm 1171 * *$ & $2879 \pm 243 * *$ \\
\hline
\end{tabular}

$V P V D$, valence-probe visual discrimination; TSVR, touchscreen serial visual reversal task; $P R L$, probabilistic reversal learning task. Group data are mean \pm standard error of the mean (SEM), collapsed across sessions and reversal phases (Early, Mid, Late) in the TSVR and VPVD task. $* p<0.05 ; * * p<0.01 ; * * * p<0.001$ vs. vehicle-treated rats in each experiment

\section{Pre-training}

We adapted the established serial PRL task (Bari et al. 2010) for touchscreen chambers controlled by ABETII software written by B.U.P. See Supplementary Table 1 for an overview. Briefly, 12 rats underwent one Habituation session where ca. 30 pellets were freely available in the food 
tray and no task was run. Next, in a single Conditioning session, two white stimuli were presented on the screen; after the rat touched either stimuli or after $30 \mathrm{~s}$ had passed, the stimuli disappeared and a pellet was delivered to the food tray. Rats earned a maximum of 100 pellets in this session. If they did not complete all trials, the session terminated after $60 \mathrm{~min}$. Next, during Must Touch training, no free pellets were delivered but rats could still press the stimuli for reward. These sessions terminated following 60 min or after 100 rewards had been earned, whichever occurred first. Next, animals were trained to initiate in the food magazine to begin a trial. This training stage was identical to Must Touch, except that all animals had to emit an additional nosepoke in the magazine to commence each trial. These sessions also terminated following either $60 \mathrm{~min}$ or after 100 pellets had been earned. Finally, all animals were trained on a Punish Incorrect stage. This was identical to the previous initiation stage except that responses at a non-target location were punished with a brief $(5 \mathrm{~s})$ timeout.

\section{Experimental procedure}

All animals were then trained on the full serial PRL procedure. This was conducted as per the final training stage, except that at the beginning of the session, one side stimulus was randomly assigned a reward probability of $80 \%$ and the other a reward probability of $20 \%$. Following eight consecutive "correct" responses (responses to the $80 \%$ reward-probability side), the contingencies reversed so that the previously $20 \%$ rewarded stimulus became $80 \%$-rewarded and vice versa. These sessions terminated following either $60 \mathrm{~min}$ or after 200 trials had been completed. Once performance stabilised at a high level, drug administration experiments commenced. This was conducted as a within-subject Latin square, with all animals receiving all doses of quinpirole and vehicle control in a counterbalanced, pseudorandom order. For these experiments, administration sessions were always separated by a baseline session with no drug administration.

\section{Statistical analyses and modelling of data from the probabilistic serial spatial reversal task}

The main measures from the PRL task were the number of reversals completed per session, the win-stay probability, i.e. $P$ (choose the same stimulus $\mid$ rewarded on the last trial), and the lose-shift probability, i.e. $P$ (choose the alternative stimulus | unrewarded on the last trial). We also analysed auxiliary measures including latency to respond and to collect rewards. Conventional statistical analyses (ANOVA) were applied to these measures.
Computational reinforcement learning modelling of choice data

In order to better describe the choice data from the PRL task, we applied a set of hierarchical Bayesian reinforcement learning models designed to reveal latent variables that were involved in behavioural choice. Four models were evaluated (see also Electronic Supplementary Material). The first contained parameters for reward rate $\left(\alpha_{\text {win }}\right)$, which described the learning rate on rewarded trials; punishment rate $\left(\alpha_{\text {loss }}\right)$, which described the learning rate on non-rewarded trials; and a softmax inverse temperature parameter $(\beta)$, which described the degree to which choices either strongly followed stimulus value (high $\beta$ ) or were more stochastic (low $\beta$ ). The second model contained all of the above parameters and an additional side stickiness parameter $(\tau)$, which was designed to capture the tendency for animals to simply repeat choices at the same spatial location. The third model had a combined learning rate for rewards and punishments, a side stickiness parameter, and an inverse temperature parameter. The final model was a version of the Experience-Weighted Attraction model, which includes a parameter for the influence of previous associations (cf. (den Ouden et al. 2013)).

All models were fitted to the behavioural data by Monte Carlo sampling in Stan 2.17.2 (Stan Development Team; $\mathrm{http}: / / \mathrm{mc}$-stan.org) and subsequently compared by bridge sampling, which generates estimates of the marginal likelihood (Gronau et al. 2017a). This was implemented via the R package "bridgesampling" (Gronau et al. 2017b) and reveals the Bayesian posterior probability of each model given both the prior model probability and empirical data. The mean values for each parameter per group from the winning model are presented alongside the Bayesian 95\% highest posterior density interval (HDI). Drug effects vs. vehicle were also sampled and evaluated as $95 \% \mathrm{HDI}$, which provides a robust posterior difference estimate for each parameter.

The parameters from the winning model were further evaluated by a set of simulations. Specifically, we simulated groups of rats ( $n=40$ per dose) with parameter values randomly drawn from the distribution of the estimated parameters from each drug group in the actual experiment $(0 ; 0.025 ; 0.1$; and $0.25 \mathrm{mg} / \mathrm{kg}$ ). Each simulated rat then completed the PRL task in a virtual environment, updating the $\mathrm{Q}$ values and probabilities of choosing left and right (see Electronic Supplementary Material for details) depending on the four individual parameters corresponding to that rat ( $\alpha_{\text {win }}, \alpha_{\text {loss }}, \tau$ and $\beta$ ) and the trialby-trial feedback from the task, including probabilistically rewarded response options $(80 \% / 20 \%)$ and reversals after 8 "correct" choices in a row.

In addition, to test whether quinpirole-induced changes in individual parameters were sufficient to affect choice behaviour, we created sets of simulated rats $(n=40$ per condition) where all but one parameter were drawn from the estimated 
parameter distribution for vehicle-treated rats; the last parameter was drawn from the parameter distribution of quinpirole rats. Finally, we tested the necessity of parameters of interest to drive the change in behaviour, by drawing e.g. $\alpha_{\text {loss }}$ from its distribution for vehicle rats and drawing the remaining three parameters $\left(\alpha_{\text {win }}, \tau\right.$, and $\left.\beta\right)$ from the relevant parameter distribution of quinpirole-treated rats.

\section{Results}

\section{Experiment 1: Optimisation of the VPVD task}

The VPVD task was optimised with regard to probe stimulus exemplar and probe trial frequency (Fig. 1a, b), so that rats displayed below-chance performance in probe trials for learning from both negative feedback $\left(\mathrm{A}-<\mathrm{C}_{50 / 50}\right)$ and positive feedback $\left(\mathrm{B}+>\mathrm{C}_{50 / 50}\right)$ immediately following reversal (Fig. 1c). This indicated that the task, at these parameters, allowed us to tap into both learned non-reward (avoiding the previously negative, now positive stimulus; $\mathrm{B}+$ ) and stimulus perseveration (approaching the previously positive, now negative stimulus; $\mathrm{A}^{-}$). All further testing was performed using these parameters.

\section{Experiment 2: Effects of D2R agonism with quinpirole on reversal learning}

Initial inspection of the reversal data after quinpirole treatment revealed that behaviour was disrupted by the highest dose $(0.5 \mathrm{mg} / \mathrm{kg})$, with rats in this group completing fewer trials than controls (one-way ANOVA: $F_{5,41}=4.59 ; p=0.002$; significant reduction in trials only at $0.5 \mathrm{mg} / \mathrm{kg}$ dose; data not shown). Quinpirole treatment also dose-dependently increased latency to collect rewards $\left(F_{5,41}=13.9 ; p<0.001\right.$; Table 2$)$ but had no impact on latency to respond $\left(F_{5,41}<1\right.$; NS). Due to the effects on trials completed, we excluded the $0.5 \mathrm{mg} / \mathrm{kg}$ dose from further analyses.

Quinpirole treatment impaired performance in the VPVD reversal learning task. On the standard $(\mathrm{A}-<\mathrm{B}+)$ trials, there was a main effect of Dose $\left(F_{4,34}=6.83, p<0.001\right)$ and a Dose $\times$ Session interaction $\left(F_{18.4,156}=2.38, p=0.002\right)$. Post hoc analysis (Sidak's method) revealed that the $0.25 \mathrm{mg} / \mathrm{kg}$ dose reduced \%Correct from session 7 onwards (See Fig. 2a). The number of errors on the standard $(\mathrm{A}-<\mathrm{B}+)$ trials were also analysed after trials were split into early $(<11$ correct in 30 trials), mid, and late ( $>19$ correct in 30 trials) phases (Alsiö et al. 2015): there was a significant effect of Dose $\left(F_{4,34}=\right.$ $2.82 ; p=0.04)$ but no Dose $\times$ Phase interaction $\left(F_{8,68}<1\right.$; NS). See Fig. 2b. Post hoc analysis (Fisher's LSD) suggested that the $0.25 \mathrm{mg} / \mathrm{kg}$ increased overall errors compared to vehicle $(p=0.025)$.
Quinpirole differentially affects learning from positive and negative feedback

The quinpirole-induced impairment of reversal learning was accompanied by a selective effect on the negative probe trials (Fig. 2c, d). When analysing the \%Optimal choice on the two types of probe trials in a (three-way) ANOVA, we observed a significant Dose $\times$ Session $\times$ Valence (positive vs. negative) interaction $\left(F_{22.6,191}=1.86 ; p=0.014\right)$, indicating that the effect of Dose differed between positive and negative probe trials across sessions.

Choice performance on the positive and negative probe trials was next analysed separately. On the positive-valence probe trials $\left(\mathrm{B}+>\mathrm{C}_{50 / 50}\right)$, there was no effect of Dose $\left(F_{4,34}=2.01\right.$; $p=0.11)$ or Dose $\times$ Session interaction $\left(F_{21.9,186}=1.22, \mathrm{NS}\right)$. On negative-valence probe trials $\left(\mathrm{A}-<\mathrm{C}_{50 / 50}\right)$, in contrast, there was a main effect of Dose $\left(F_{4,34}=8.86, p<0.001\right)$ and a significant Dose $\times$ Session interaction $\left(F_{30.6,260}=2.37\right.$, $p<0.001)$. Sidak's post hoc comparisons revealed that the $0.25 \mathrm{mg} / \mathrm{kg}$ dose impaired performance consistently from session 7 onwards. Impairments were also observed for the $0.1 \mathrm{mg} / \mathrm{kg}$ dose from session 9 onwards.

When \%Correct on the standard $(\mathrm{A}-<\mathrm{B}+)$ trials of the first day was analysed separately, there was no significant main effect of Dose $\left(F_{4,43}=1.65\right.$; NS). When performance on the probe trials on the first day was examined using a two-way ANOVA with Dose as a 5-level between-subjects factor and Valence as a 2-level within-subjects factor, there were also no effect of Dose $\left(F_{4,34}=2.11 ; p=0.10\right)$ or Dose $\times$ Valence interaction $\left(F_{4,34}<1\right.$; NS), but a significant effect of Valence $\left(F_{1,34}=11.4 ; p=0.002\right)$.

It should be noted that the exclusion or inclusion of the $0.5 \mathrm{mg} / \mathrm{kg}$ quinpirole group did not affect the overall pattern of results. Importantly, the three-way interaction with Dose $\times$ Session $\times$ Valence remained significant also when the $0.5 \mathrm{mg} / \mathrm{kg}$ dose was included $\left(F_{31.1,255}=1.82 ; p=0.007\right)$. In addition, previous drug history (SKF81297, Experiment 3, see below) did not significantly affect any choice measure in the quinpirole experiment (main effect and all interactions, $p>0.1$ ) and the three-way interaction Dose (of quinpirole) $\times$ Session $\times$ Valence remained significant in analyses of variance where SKF81297 drug history was included as a between-subjects factor, regardless of whether all quinpirole doses were analysed together $\left(F_{30.7,178}=1.94 ; p=0.004\right)$ or whether the highest quinpirole dose was excluded $\left(F_{21.8,131}=2.08 ; p=0.006\right)$.

\section{Experiment 3: No effect of the D1R agonist SKF81297 on choice behaviour in the VPVD task}

The D1R agonist SKF81297 had no appreciable effects on reversal learning overall (Fig. 3a). In a two-way ANOVA, there was no main effect of Dose $\left(F_{2,45}<1\right.$; NS) on performance on the standard $(\mathrm{A}-<\mathrm{B}+)$ trials, and no Dose $\times$ 
Fig. 2 The dopamine D2-like receptor agonist quinpirole impaired visual reversal learning in the novel VPVD reversal task ( $n=7-8$ for each group). a Quinpirole at $0.25 \mathrm{mg} / \mathrm{kg}$ reduced correct responses on standard A$<\mathrm{B}+$ trials. b Quinpirole at $0.25 \mathrm{mg} / \mathrm{kg}$ increased the number of errors on standard $\mathrm{A}-<\mathrm{B}+$ trials across the learning phases (early: $<11$ correct in any 30 trials; late: $>19$ correct in any 30 trials, but before the criterion of 24 correct). $\mathbf{c}$ There was no effect on performance on the $\mathrm{B}+>\mathrm{C}_{50 / 50}$ trials, indicating intact learning from positive feedback. d Quinpirole dose-dependently impaired performance on the $\mathrm{A}^{-}<$ learning from losses. Note that rats treated with quinpirole $0.25 \mathrm{mg} / \mathrm{kg}$ fail to improve over chance performance on negative probe trials across the 14 days of testing. Graphs show mean \pm SEM for each dose and session $\mathrm{C}_{50 / 50}$ trials, indicating impaired

a

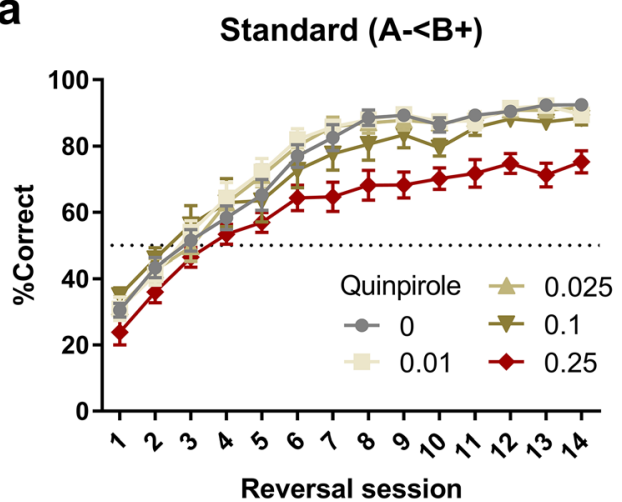

C

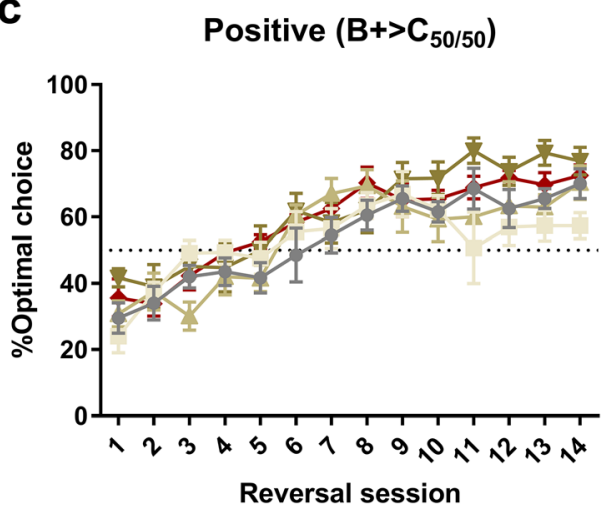

Fig. 3 Lack of impact of the D1 receptor agonist SKF81297 on reversal learning in the VPVD task. SKF81297 did not affect learning overall at either $0.1 \mathrm{mg} / \mathrm{kg}(n=16)$ or $0.25 \mathrm{mg} / \mathrm{kg}$ $(\mathrm{n}=16)$ vs. vehicle $(n=16)$. a $\%$ Correct on standard $\mathrm{A}-<\mathrm{B}+$ trials across the 14 days of treatment. b Numbers of errors on standard $\mathrm{A}-<\mathrm{B}+$ trials (probe trials excluded) during early, mid, and late phases of the reversal. c No significant effect of SKF81297 on performance on positive probe trials. d) No effect of SKF81297 on choice behaviour on negative probe trials. Graphs show mean \pm SEM for each dose and session a

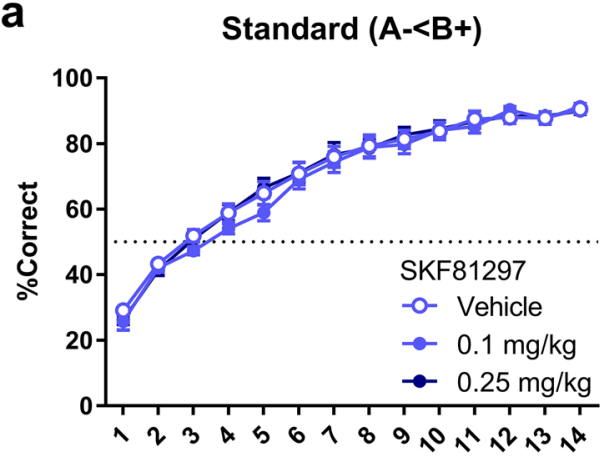

Reversal session

C

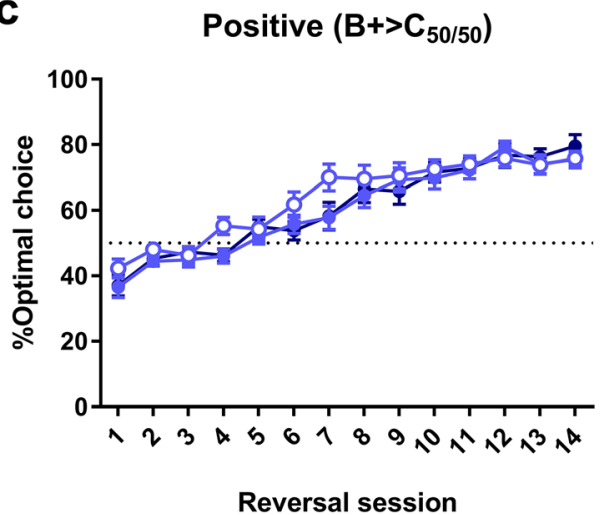

b

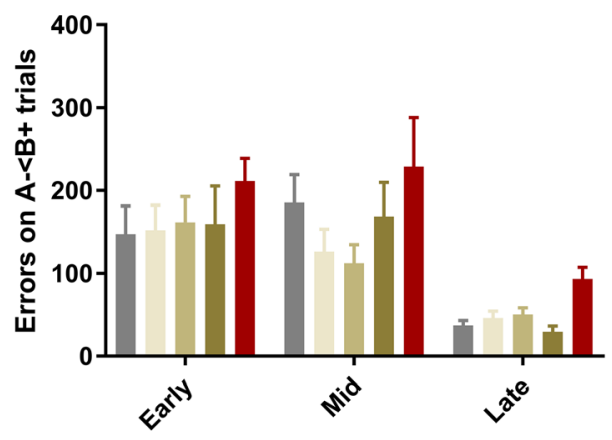

d

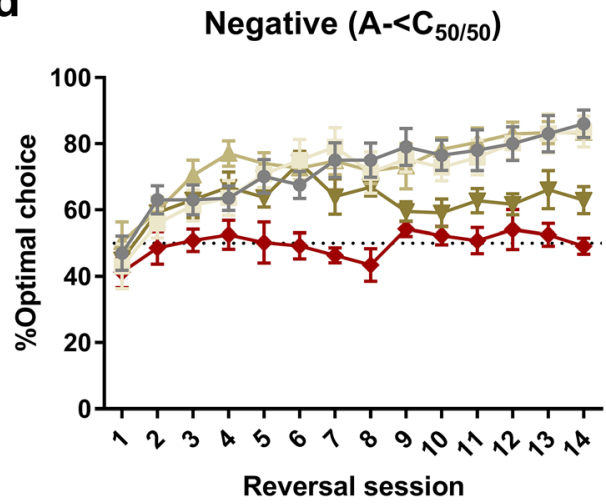

b

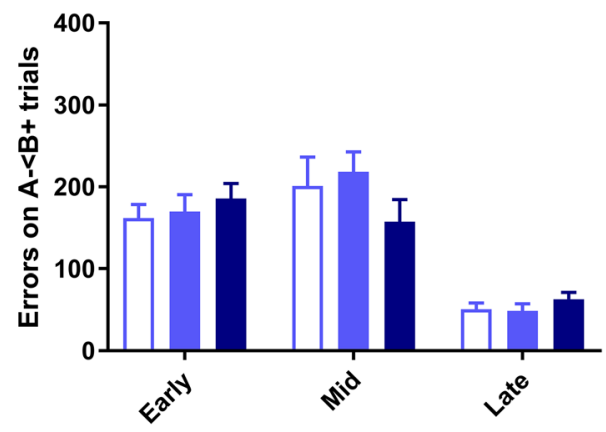

d Negative $\left(A-<C_{50 / 50}\right)$

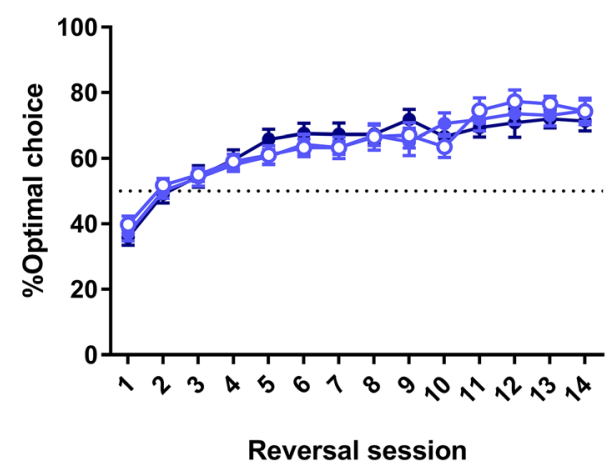


Session interaction $\left(F_{8.39,189}<1\right.$; NS). Performance on the standard $(\mathrm{A}-<\mathrm{B}+)$ trials were next split into early, mid, and late phases, as above, and analysed in a two-way ANOVA. There was no significant effect of Dose $\left(F_{2,45}<1\right.$; NS) or a Dose $\times$ Phase interaction $\left(F_{3.11,69.9}=1.95 ; p=0.13\right)$ on errors in the different phases (Fig. 3b).

The combined effects of Dose and Session on \%Optimal choice were investigated in a three-way ANOVA (Fig. 3c, d). There was no Dose $\times$ Session $\times$ Valence interaction $\left(F_{11.1,251}=\right.$ 1.25 , NS), and also no significant main effect of Dose in the full model $\left(F_{2,45}<1\right.$; NS). Despite the lack of a significant threeway interaction, the performance on the positive and negative probe trials was next analysed separately for potential trends in the data. On positive probe trials, there was no significant effect of Dose $\left(F_{2,45}<1\right.$; NS $)$ and no significant Dose $\times$ Session interaction $\left(F_{12.6,283}=1.14 ; \mathrm{NS}\right)$. On negative probe trials, there was similarly no effect of Dose $\left(F_{2,45}<1\right.$; NS) and no significant Dose $\times$ Session interaction $\left(F_{12.9,290}<1\right.$; NS).

SKF81297 did not affect latencies to respond at the stimuli $\left(F_{2,45}=1.80 ; \mathrm{NS}\right)$ but did have an impact on reward collection latencies $\left(F_{2,45}=4.41 ; p=0.018\right)$; post hoc analyses revealed that the $0.25 \mathrm{mg} / \mathrm{kg}$ dose increased the latency to collect the reward (Table 2).

\section{Experiment 4: Effects of D1R and D2R antagonism on reversal learning}

In a preliminary experiment, we evaluated a range of doses for $\mathrm{SCH} 39166(0 ; 0.025 ; 0.05 ; 0.1 \mathrm{mg} / \mathrm{kg})$ and raclopride $(0 ;$ $0.015 ; 0.03 ; 0.06 \mathrm{mg} / \mathrm{kg}$ ) on the touchscreen serial visual reversal task (Electronic Supplementary Material). Doses used for the VPVD task were based on a lack of effect on response latencies; there were also no effects of SCH39166 or raclopride on errors on the serial visual task (Supplementary Fig. 2).

In the VPVD reversal task, no significant overall effects were detected after either D1R antagonism (SCH39166) or D2R antagonism (raclopride) compared to vehicle-treated rats (Fig. 4a). Percentage correct on standard $(\mathrm{A}-<\mathrm{B}+)$ trials was investigated with a two-way ANOVA with Treatment (vehicle, SCH39166, or raclopride) as a between-subjects factor and Session as a within-subjects factor (10 levels). We observed no effect of Treatment $\left(F_{2,44}<1\right.$; NS) and no Treatment $\times$ Session interaction $\left(F_{5.56,122}=1.29 ; \mathrm{NS}\right)$. We also analysed the performance on the $\mathrm{A}-<\mathrm{B}+$ trials from the perspective of different phases in reversal learning (early, mid and late; Fig. $4 \mathrm{~b}$ ). There was no main effect of Treatment $\left(F_{2,45}<1\right.$; NS) and no Treatment $\times$ Phase interaction $\left(F_{3.17,71.3}<1 ; \mathrm{NS}\right)$ in a two-way ANOVA.

\section{Transient effect of D1R antagonism on positive feedback}

Performance on the probe trials was investigated next (Fig. $4 \mathrm{c}, \mathrm{d})$. We observed no significant three-way Treatment $\times$ Session $\times$ Valence interaction $\left(F_{10.1,221}<1 ; \mathrm{NS}\right)$ and no main effect of Treatment $\left(F_{2,44}<1, \mathrm{NS}\right)$ in the full model. To test the a priori hypothesis that dopamine D1-receptor antagonism impairs learning from positive feedback, we next investigated the effects of SCH39166 and raclopride on positive and negative probe trials separately (despite a lack of a significant three-way interaction). On positive probe trials, there was no main effect of Treatment $\left(F_{2,44}<1\right.$; NS $)$ and no Treatment $\times$ Session $\left(F_{9.88,217}=1.49 ; p=0.15\right)$. On negative probe trials, there was similarly no effect of Treatment $\left(F_{2,44}<1\right.$; NS $)$ and no significant Treatment $\times$ Session interaction $\left(F_{11.2,247}<1\right.$; NS).

We also tested the hypothesis that D1- and D2-receptor antagonism preferentially affects early reversal learning. In a oneway ANOVA with Treatment as the between-subject factor (3 levels), we found no significant effect on \%Correct on the standard $(\mathrm{A}-<\mathrm{B}+)$ trials on the first day of reversal $\left(F_{2,45}<1\right.$; NS). In a two-way ANOVA with Treatment as a between-subjects factor and Valence as a within-subjects factor, we observed a significant main effect of Treatment $\left(F_{2,45}=5.45 ; p=0.008\right)$ but no effect of Valence $\left(F_{1,45}<1\right.$; NS) and no Treatment $\times$ Valence interaction $\left(F_{2,45}<1\right.$; NS). As we had a priori expectations about differential effects across learning from positive and negative feedback, we investigated simple main effects despite the lack of a significant two-way interaction. Analysis of simple main effects using Fisher's LSD comparisons revealed a significant effect of SCH39166 on the positive probe trials on the first day $(p=0.033)$; all other comparisons were non-significant.

In agreement with our preliminary experiments, there was no effect of SCH39166 or raclopride dose on latency to respond in a one-way ANOVA $\left(F_{2,45}=1.83\right.$; NS); in a separate ANOVA, there was also no significant effect on latency to collect the reward $\left(F_{2,45}=1.73\right.$; NS). See Table 2 .

\section{Experiment 5: Effects on D2R agonism on a spatial PRL task}

Quinpirole impaired learning and increased latencies to respond and collect rewards on the PRL (Fig. 5a-c; Table 2). In a oneway ANOVA, quinpirole dose-dependently decreased the number of reversals completed $\left(F_{3,33}=13.4 ; p<0.001\right)$; post hoc analyses revealed that this effect was significant at both $0.1 \mathrm{mg} / \mathrm{kg}$ and $0.25 \mathrm{mg} / \mathrm{kg}$ quinpirole (Fig. 5a). In a two-way ANOVA with Trial Type (win-stay, lose-shift) and Dose (4 levels) as withinsubject factors, there was a main effect of Dose $\left(F_{3,33}=13.8\right.$; $p<0.001)$ but no Dose $\times$ Trial Type interaction $\left(F_{3,33}<1 ; \mathrm{NS}\right)$. We nevertheless investigated the trial types separately, as these can be speculated to relate to learning from positive and negative feedback, respectively (but see the computational analysis below, for more robust measures). Quinpirole had a significant impact on win-stay probability $\left(F_{2.1 .23 .1}=11.0 ; p<0.001\right)$; post hoc analyses revealed significantly decreased values for both $0.1 \mathrm{mg} / \mathrm{kg}$ and $0.25 \mathrm{mg} / \mathrm{kg}$ (Fig. 5b). There was also a significant effect of quinpirole on lose-shift performance $\left(F_{3,33}=6.41 ; p=\right.$ 0.002 ); this effect was driven by the $0.25 \mathrm{mg} / \mathrm{kg}$ treatment 
Fig. 4 Performance on the VPVD reversal task after dopamine receptor antagonism. D2-like receptor antagonism (raclopride; $0.03 \mathrm{mg} / \mathrm{kg} ; n=13$ ) and D1-like receptor antagonism (SCH39166; $0.05 \mathrm{mg} / \mathrm{kg}, n=14$ ) had no significant effect versus vehicle treatment (saline; $n=20$ ). a $\%$ Correct over each of 10 sessions. $\mathbf{b}$ No effect on number of errors on standard $\mathrm{A}-<\mathrm{B}+$ trials committed during each of three learning phases. c, $\mathbf{d}$ Performance on probe trials. Raclopride and SCH39166 did not significantly affect learning overall on either positive $\left(\mathrm{B}+>\mathrm{C}_{50 / 50}\right)$ or negative $\left(\mathrm{A}-<\mathrm{C}_{50 / 50}\right)$ trials. The graphs show mean \pm SEM for each dose and session a

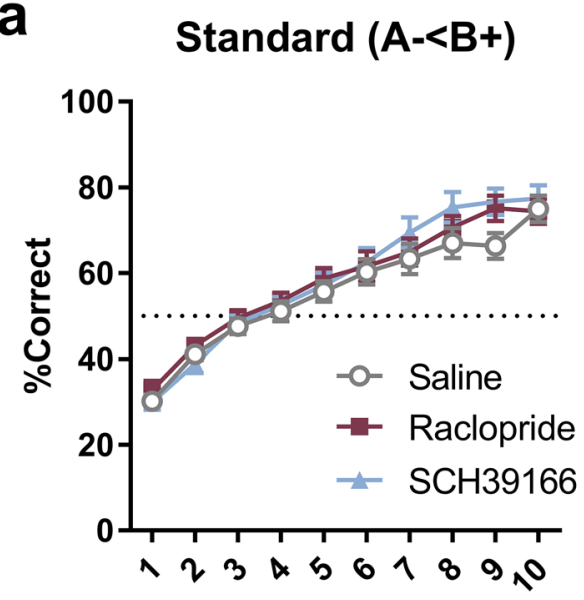

Reversal session
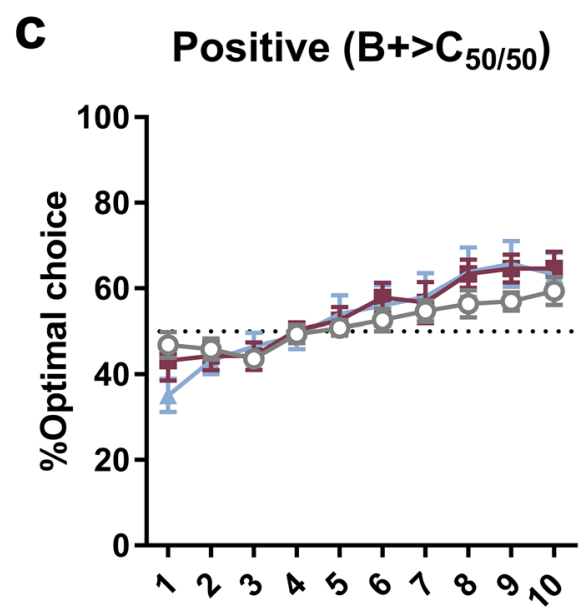

Reversal session b

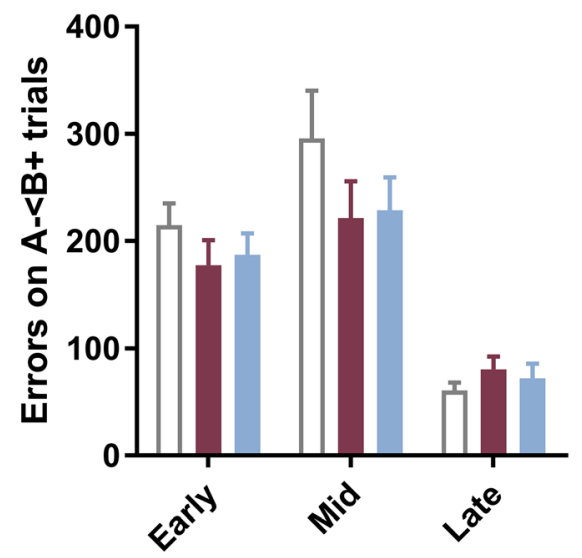

d Negative $\left(A-<C_{50 / 50}\right)$

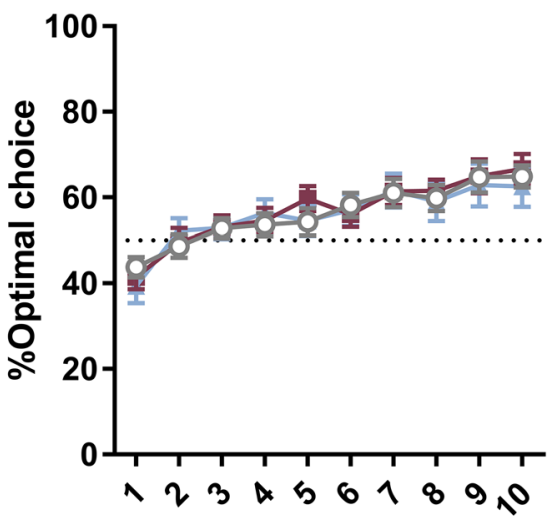

Reversal session
(Fig. 5c). Furthermore, quinpirole increased latencies both to respond on the screen (one-way ANOVA; $F_{1.71,17.1}=16.5 ; p$ $<0.001$ ) and to collect the sugar pellet (one-way ANOVA; $\left.F_{1.51,15.1}=9.25 ; p=0.004\right)$ on rewarded trials. Post hoc analyses showed that all doses of quinpirole increased both latency to respond and collect rewards in the PRL (Table 2).

\section{Hierarchical Bayesian modelling of PRL choice data}

We next used hierarchical Bayesian analysis of reinforcement learning to sample latent variables influencing behaviour in the probabilistic spatial serial reversal task. Four different models were compared; the best description of the choice data (via bridge-sampled maximum likelihoods) was found to be the model containing separate learning rates for wins $\left(\alpha_{\text {win }}\right)$ and losses $\left(\alpha_{\text {loss }}\right)$, a softmax inverse temperature parameter $(\beta)$ and a side stickiness parameter $(\tau)$. For details, see Electronic Supplementary Material.
We explored the effect of drug treatment on the posterior distributions of the group means for $\alpha_{\text {win }}, \alpha_{\text {loss }}, \beta$, and $\tau$ (Fig. $5 \mathrm{~d})$. For $\alpha_{\text {win }}$ (learning rate for wins), $0.025 \mathrm{mg} / \mathrm{kg}$ increased this measure relative to the vehicle condition $(0 \notin 95 \%$ HDI for group differences). Conversely, $0.1 \mathrm{mg} / \mathrm{kg}$ decreased $\alpha_{\text {win }}$ relative to vehicle treatment $(0 \notin 95 \%$ HDI for group differences). In contrast, the $0.25 \mathrm{mg} / \mathrm{kg}$ dose did not affect $\alpha_{\text {win }}$. There was a sharp decrease in $\alpha_{\text {loss }}$ (learning rate for losses) at the highest dose of quinpirole $(0.25 \mathrm{mg} / \mathrm{kg})$ compared to the vehicle condition $(0 \notin 95 \%$ HDI for group differences). No other doses exerted an effect on this parameter. Additionally, high-dose $(0.25 \mathrm{mg} / \mathrm{kg})$ quinpirole increased $\beta$ (inverse temperature) relative to vehicle treatment $(0 \notin 95 \%$ HDI for group differences), whereas other doses did not affect this parameter. Finally, low-dose quinpirole $(0.025 \mathrm{mg} / \mathrm{kg})$ decreased $\tau$ (side stickiness) relative to vehicle treatment $(0 \notin 95 \%$ HDI for group differences), but no other differences in which the 95\% HDI did not contain 0 were detected on this measure. 

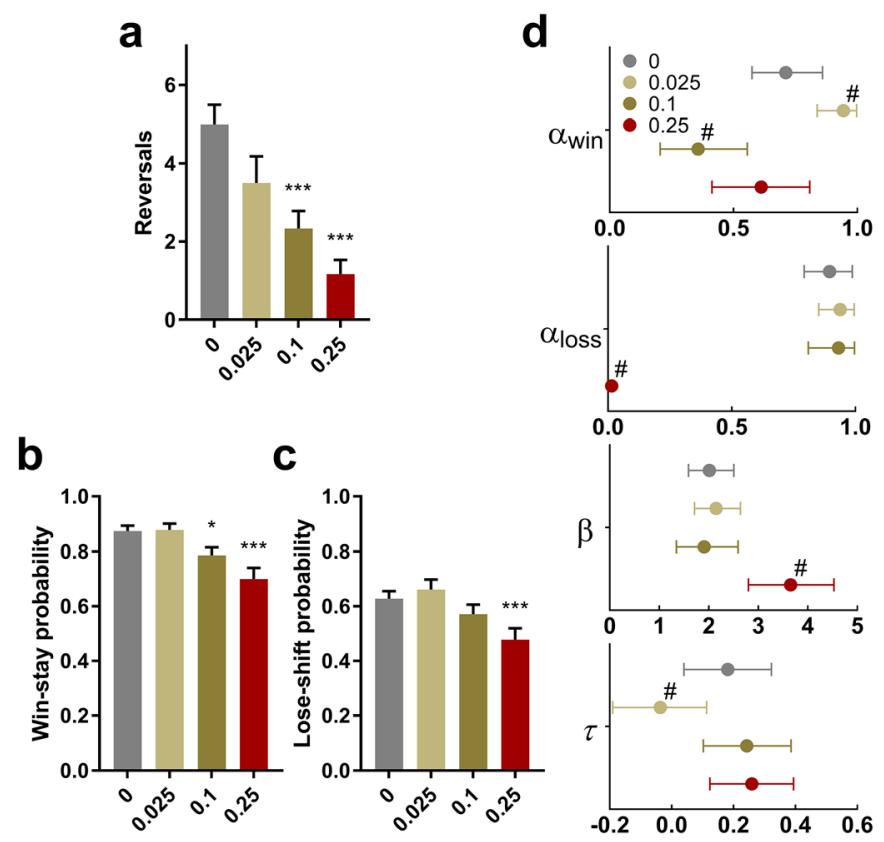
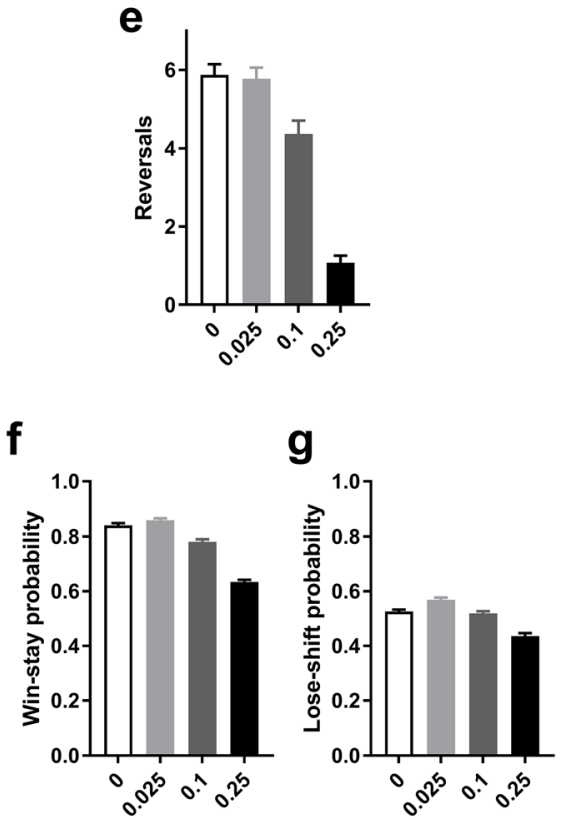

Fig. 5 The D2R agonist quinpirole impaired reversal learning in the PRL task. a Dose-dependent decrease in the number of reversals completed after quinpirole injections (mean $\pm \mathrm{SEM}$ ). $\mathbf{b}$, $\mathbf{c}$ Quinpirole impaired both win-stay (b) and lose-shift (c) performance (mean \pm SEM). d 95\% highest posterior density intervals (HDI) for parameters estimated by hierarchical Bayesian analysis of trial-by-trial choice data from the PRL task. The best model was a reinforcement learning account with separate learning rates for wins $\left(\alpha_{\text {win }}\right)$ and losses $\left(\alpha_{\text {loss }}\right)$, inverse temperature $(\beta)$, and side stickiness $(\tau)$. Quinpirole $0.25 \mathrm{mg} / \mathrm{kg}$ impaired learning rate after losses $\left(\alpha_{\text {loss }}\right)$ without affecting learning rate for wins $\left(\alpha_{\text {win }}\right)$. This dose also increased the inverse temperature. $\mathbf{e}-\mathbf{g}$ Using the winning model, we simulated rats performing the reversal task in silico and updated their expected outcomes (Q values; see Supplementary Online Material) on a trial-bytrial basis using feedback such as probabilistically rewarded responses and reversals after 8 correct responses in a row. For each simulated group ( $n=40$ /dose; graphs show mean $\pm \mathrm{SEM}$ ), parameter values were randomly drawn from the estimated distribution of the actual rats at the corresponding dose. e Dose-dependent decrease in the number of reversals in the simulation. $\mathbf{f}, \mathbf{g}$ Win-stay and lose-shift analysis of choice data from the simulated rats reveals that the behaviour of the actual rats is recovered by the winning model. $* p<0.05$ vs. vehicle; $* * * p<0.001$ vs vehicle; \#the 95\% HDI for the difference score (vs. vehicle) excluded zero, i.e. there is a $>95 \%$ probability that the drug effect was non-zero

\section{Simulated task performance: posterior predictive check and role of individual model parameters in driving reversal impairment}

To interrogate the validity of the winning model and better understand the contribution of changes in reinforcement learning parameters to overall performance, we simulated the choice behaviour of agents on the serial PRL task based on the extracted parameters in the winning model. The simulations closely matched the raw data on the main task measures, with dosedependent trends on reversals completed (Fig. 5e) and win-stay and lose-shift proportions (Fig. 5f, g).

Next, we reasoned that the changes in task performance detected following high-dose quinpirole administration could be attributed to either the increase in $\beta$ or the reduction in $\alpha_{\text {loss. }}$. To distinguish between these competing explanations, we carried out simulations of task performance where virtual agents would be allocated one extracted parameter from the quinpirole group $(0.25 \mathrm{mg} / \mathrm{kg})$ and maintaining all other parameters at vehicle levels (Clarke et al. 2014). This revealed that simulating performance with only the high-dose $\alpha_{\text {loss }}$ values was sufficient to closely replicate the reversal (Fig. 6a) and win-stay/lose-shift values (Fig. 6b, c) from the high-dose quinpirole group; in contrast, agents with the highdose $\beta$ values were, in fact, better than simulated vehicle rats on both reversals completed and win-stay probability (Fig. $6 \mathrm{a}-\mathrm{c})$.

Having established that the change in high-dose $\alpha_{\text {loss }}$ was sufficient to replicate the impairments in task performance, we also tested whether it was necessary to bring about this pattern of results (Fig. 6d-f). To achieve this, we carried out further simulations in which one parameter was set to vehicle levels and the others were maintained at high-dose quinpirole levels. This revealed that the reduction in $\alpha_{\text {loss }}$ was necessary to recapitulate the impairments that were observed in rats treated with high-dose quinpirole. This effect was observed in number of reversals completed (Fig. 6d) and in win-stay probability (Fig. 6e), but less so in the lose-shift performance (Fig. 6f). 

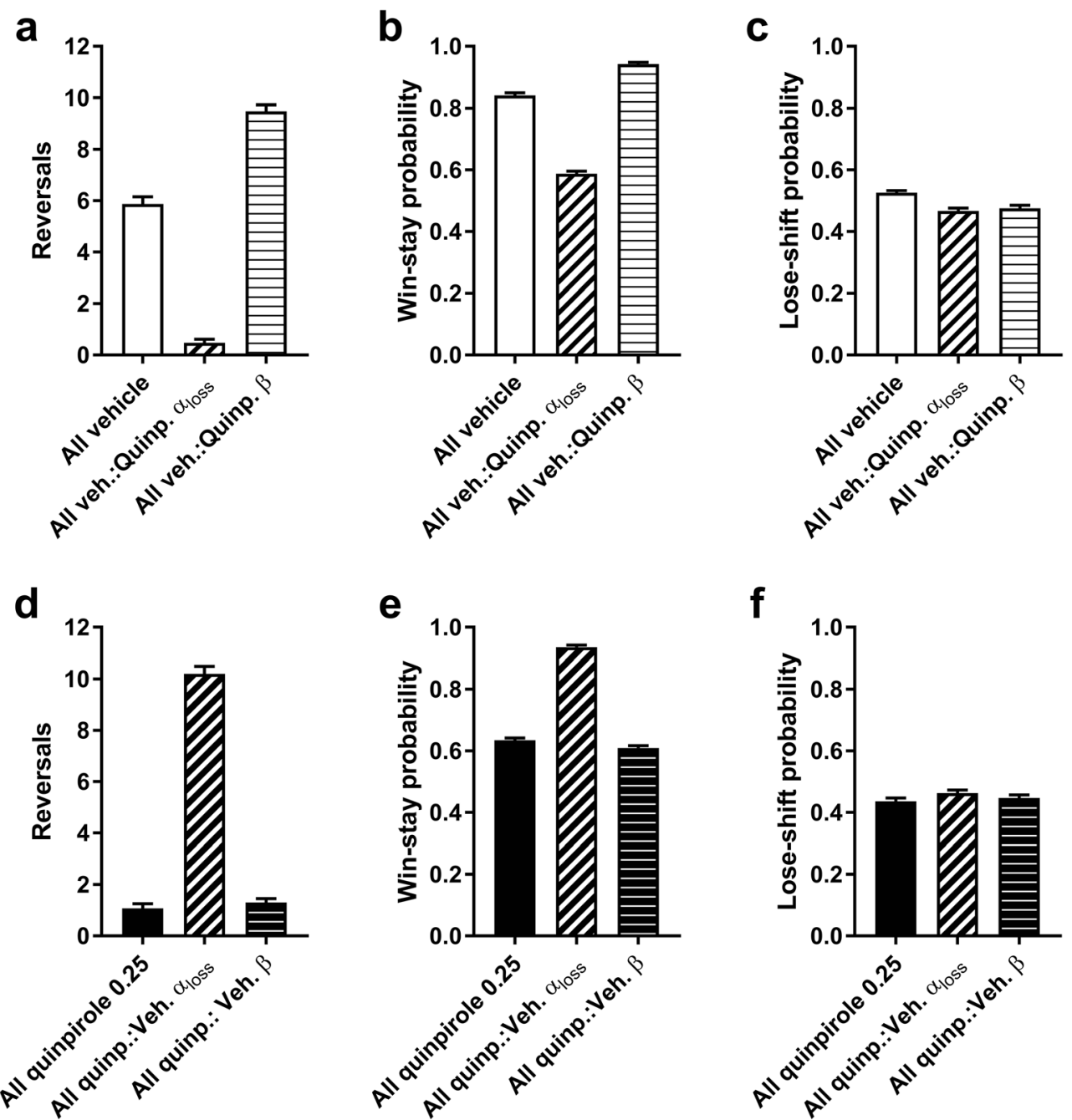

Fig. 6 Simulations reveal that the effects of quinpirole $0.25 \mathrm{mg} / \mathrm{kg}$ on the $\alpha_{\text {loss }}$ parameter is sufficient and necessary to drive reversal learning impairment. a Test for sufficiency of the $\alpha_{\text {loss }}$ parameter to drive reversal impairment. In simulated vehicle-treated rats ("All vehicle"; see Fig. 5), impaired reversal learning is observed when the $\alpha_{\text {loss }}$ parameter is replaced by values drawn from the estimated distribution of quinpirole $0.25 \mathrm{mg} / \mathrm{kg}$ rats (“All veh.:Quinp. $\alpha_{\text {loss }}$ "). In contrast, replacing the $\alpha_{\text {loss }}$ parameter with $\beta$ drawn from the distribution of quinpirole $0.25 \mathrm{mg} / \mathrm{kg}$ rats (“All veh.: Quinp. $\beta$ ”) actually improves simulated performance, as measured by reversals completed. b The same pattern is observed on win-stay probabilities, where "All veh.:Quinp. $\alpha_{\text {loss" }}$ "rats perform worse than both "All vehicle" and "All veh.: Quinp. $\beta$ rats". c On lose-shift probabilities, simulated vehicle-treated rats with either the $\alpha_{\text {loss }}$ or the $\beta$ drawn from the distribution of quinpirole $0.25 \mathrm{mg} / \mathrm{kg}$ rats

\section{Discussion}

We introduce a novel touchscreen paradigm that enables investigation of how positive and negative feedback shape behaviour in visual reversal learning. This is achieved by intermittently inserted probe trials that inform how subjects track specific stimulus values across changing stimulus-reward contingencies. In order to exploit the translational potential of the touchscreen display impaired performance on the virtual task. $\mathbf{d}$ Test for necessity of the $\alpha_{\text {loss }}$ parameter to drive reversal impairment. Simulated $0.25 \mathrm{mg} / \mathrm{kg}$ quinpirole rats ("All quinpirole 0.25 ") perform the virtual task poorly (cf. Figure 5). Replacing the $\alpha_{\text {loss }}$ of these simulated rats with the values drawn from the distribution of vehicle-treated rats ("All quinp.:Veh. $\alpha_{\text {loss" }}$ ") restores performance on the virtual task. In contrast, replacing only the $\beta$ with values drawn from vehicle rats ("All quinp.:Veh. $\beta$ ") does not improve performance as measured by the number of reversals. e "All quinp.:Veh. $\alpha_{\text {loss }}$ " rats outperform both "All quinpirole 0.25 " and "All quinp.:Veh. $\beta$ " on the win-stay probabilities. f On lose-shift probabilities, there were no differences between "All quinpirole 0.25 " rats and the "All quinp.:Veh. $\alpha_{\text {loss }}$ " and "All quinpirole 0.25 " groups. Graphs show mean $\pm \mathrm{SEM} ; n=40$ for each condition

methodology, we tested two hypotheses pertaining to dopaminergic influences on reversal learning, based in part on the reinforcement learning data from the probabilistic selection task in humans (Frank et al. 2004, 2007). We found strong evidence for the hypothesis that D2R agonism would impair reversal learning by selectively blocking learning from losses. In contrast, we found only weak evidence for an impact of D1R antagonism on learning from positive feedback in the visual task. The 
selective impairment in learning from negative feedback after D2R agonism was substantiated using computational analysis from another, spatial probabilistic reversal task.

\section{D2R stimulation selectively blunts learning from losses in reversal learning}

Quinpirole treatment severely impaired reversal learning at the higher end of the dose range in both deterministic visual and probabilistic spatial tasks. Whereas these observations are supported by previous studies where D2R agonism impaired reversal learning in rats (Boulougouris et al. 2009), non-human primates (Smith et al. 1999) and healthy volunteers (Mehta et al. 2001), as well as by experiments linking variation in the DRD2 gene to reversal learning (Smith et al. 1999), our data extend such findings by showing a dose-dependent and highly selective effect of quinpirole on learning from negative feedback in the novel VPVD reversal task for rats. Even after 14 days of training, animals receiving high doses of quinpirole could not discriminate between the non-rewarded response option $\left(\mathrm{A}^{-}\right)$and the probabilistically reinforced probe stimulus; at this stage, the rats had learned to choose the $\mathrm{B}+$ on the positive probe trials with high accuracy. Under the assumption that quinpirole at the relevant doses $(\geq 0.1 \mathrm{mg} / \mathrm{kg})$ act on postsynaptic D2R in the striatum to inhibit the activity of striatopallidal neurons, our data provide support for the view that the indirect pathway of the basal ganglia predominantly contributes to learning from negative feedback, or avoidance learning (Cox et al. 2015; Frank et al. 2004). Whereas this interpretation needs to be confirmed in future studies directly manipulating striatopallidal neurons or D2R within the striatum, the present study adds receptor specificity to previous pharmacological data linking hyperdopaminergic states in the rat to impaired learning from losses in reversal learning (Verharen et al. 2018). In addition, the strong link between D2R and learning from losses suggests a psychological mechanism behind enhanced sensitivity to negative feedback and concomitant risk aversion after D2R pharmacology and interrogation of D2R-positive neurons in the nucleus accumbens in the study by Zalocusky et al. (Zalocusky et al. 2016).

Quinpirole also impaired performance in the PRL task, where the number of reversals passed, as well as win-stay and lose-shift behaviour, were all reduced in a dose-dependent manner. Strikingly, parameter estimation using hierarchical Bayesian analysis revealed a complete blockade of learning from negative feedback $\left(\alpha_{\text {loss }}\right)$ at the $0.25 \mathrm{mg} / \mathrm{kg}$ dose. In contrast, there was no effect on learning from positive feedback $\left(\alpha_{\text {win }}\right)$ at this dose, although lower doses tended to either enhance $(0.025 \mathrm{mg} / \mathrm{kg})$ or reduce $(0.1 \mathrm{mg} / \mathrm{kg})$ this parameter. The $0.25 \mathrm{mg} / \mathrm{kg}$ dose also increased the inverse temperature parameter, $\beta$. Elevated $\beta$ indicates higher reinforcement sensitivity (less randomness or "exploring"), suggesting that rats on high-dose quinpirole were more guided by the expected outcomes of responses; i.e., that rats would obey the trial-bytrial Q values and "exploit" rather than "explore". Hence, impairments in reversal learning could logically be driven by either decreased $\alpha_{\text {loss }}$ or increased $\beta$ (or their combination). (Note that exploiting the expected value after a contingency reversal leads to perseveration on the task, as long as the $Q$ value for the previously correct, now incorrect choice remains high.)

We used simulations to estimate the causal contribution to reversal-learning deficits of the parameters that were affected by $0.25 \mathrm{mg} / \mathrm{kg}$ quinpirole, i.e. $\alpha_{\text {loss }}$ and $\beta$. We found that simulated "vehicle" rats, whose values for the $\alpha_{\text {loss }}$ parameter were replaced with values drawn from the " $0.25 \mathrm{mg} / \mathrm{kg}$ quinpirole" group, were as poor on the virtual task as were the simulated " $0.25 \mathrm{mg} / \mathrm{kg}$ " rats. In addition, we found that simulated "quinpirole 0.25 " $\mathrm{mg} / \mathrm{kg}$ rats, whose values for the $\alpha_{\text {loss }}$ parameter was replaced with values drawn from the "vehicle" group, were significantly better than " $0.25 \mathrm{mg} / \mathrm{kg}$ " rats. No such effects were observed for $\beta$. This suggests that the steep reduction in the $\alpha_{\text {loss }}$ parameter is both sufficient and necessary for the impairments observed after $0.25 \mathrm{mg} / \mathrm{kg}$ quinpirole treatment. Taken together, the quinpirole data from both tasks reveal an apparently complete blockade in updating behaviour in response to losses in reversal learning, manifested as an inability to learn to avoid the CS- in the visual setting and an $\alpha_{\text {loss }}$ approaching zero in the PRL.

\section{D2R stimulation does not affect learning from positive feedback in the VPVD task}

Quinpirole had no effect on performance on the positive probe trials in the visual setting, and a less consistent effect on learning rate for wins in the spatial PRL task. Whereas a lack of effect of D2R agonism on learning from positive feedback in the visual task is in agreement with our hypothesis and the reinforcement learning literature (Cox et al. 2015), the finding is at odds with other results. For instance, studies by Groman and colleagues showed that the D2R binding in the striatum of vervet monkeys correlated with reactivity to positive feedback in a reversal task (Groman et al. 2014, 2011). However, the method used to measure learning from positive feedback in those studies was win-stay behaviour. In the present PRL data, we observed a strong reduction in win-stay probability in the $0.25 \mathrm{mg} / \mathrm{kg}$ group, but this did not, however, translate to altered $\alpha_{\text {win. }}$. It is tempting to suggest that computational modelling provides a more nuanced account of behaviour than does the win-stay analysis, by taking factors other than the immediate response to reward into account when interpreting subjects' choices. In agreement with this, Verharen and colleagues recently found reduced win-stay probability in a spatial deterministic reversal task after cocaine and amphetamine pre-treatment, but a selective effect on $\alpha_{\text {loss }}$ in the computational analysis (Verharen et al. 2018). Evidence in human volunteers describes how D2R antagonism, which had no 
effect in our visual task, affected choice performance (inverse temperature, $\beta$ ) but not reinforcement learning per se (learning rate, $\alpha$ ) in a task where learning was guided by rewards, whereas no such effect was observed when learning was driven by negative reinforcement (Eisenegger et al. 2014; Pessiglione et al. 2006).

\section{Low doses of quinpirole affect collection latencies not choice performance}

Lower doses of quinpirole $(\leq 0.025 \mathrm{mg} / \mathrm{kg})$, which may act predominantly on presynaptic receptors (Ford 2014), failed to alter choice performance in the visual paradigm. Nevertheless, reward collection latencies were significantly slower at this dose and upwards, indicating blunted motivation for the reward. This shows that the $0.025 \mathrm{mg} / \mathrm{kg}$ dose was biologically active and suggests that there is a dissociation between lower and higher quinpirole doses on motivational and cognitive aspects of the task. Speculatively, quinpirole reduces motivation at lower doses by acting on presynaptic autoreceptors to inhibit activity in midbrain dopamine neurons. In line with this view, quinpirole microinfusions into the ventral tegmental area have been reported to reduce motivation for sucrose and ethanol (Hodge et al. 1993), and RNA interference of D2 receptors (hence, reduced D2 autoreceptor activity) in the ventral tegmental area increases motivation for sucrose and drug reward (de Jong et al. 2015). Such presynaptic effects appear insufficient to change reinforcement learning, both after D2R silencing (de Jong et al. 2015) and in the present data set.

\section{D1R and positive feedback}

Dopamine D1R antagonism had no overall effect on reversal learning, but caused a transient decrease in performance on the positive probe trials, indicating impaired learning on the very first reversal session. Thus, our hypothesis, that learning from positive feedback would be selectively impaired by D1R antagonism, gained no conclusive support. Nevertheless, our observation of no overall impairment of D1R antagonism on reversal learning is in agreement with a lack of effect of systemic SCH23390 treatment on reversal learning in vervet monkeys (Lee et al. 2007). Similarly, D1R agonism had no effect on any of the main measures in this experiment; this is in apparent contradiction with a previous reversal-learning experiment where a transient effect on the first sessions was observed after injections of the same drug in mice (Izquierdo et al. 2006). It is conceivable that the performance-impairing effects of D1R agonism and antagonism on neurons in the striatum are confounded by enhancing effects at other sites (e.g. in the cortex, although see (Calaminus and Hauber 2008)). In addition, our prediction of performance-impairing effects of D1R antagonists was based on reports from discrimination learning tasks (e.g. (Frank et al. 2007; Kravitz et al.
2012)), and we acknowledge that D1R may play additional or opposing roles during reversal learning, where previous associations have to be overcome for successful task performance. Such opposing effects may be dose-dependent, and potentially unmasked at alternative dose intervals than those used in the current set of experiments. Taken together, future studies should focus on the effects of D1R manipulations on, e.g. initial visual discrimination learning or investigate the effects of local micro-infusion of D1R agents into brain areas of interest in rats performing reversal-learning tasks. Furthermore, the failure of any dopamine agents tested here to affect learning to approach the positive stimulus warrants the investigation of drugs acting on other neuromodulators or neurotransmitter systems to identify the mechanisms of positive feedback in reversal learning.

\section{Strengths and weaknesses of the VPVD task}

The design of the VPVD task comes with inherent strengths and weaknesses. The main strength is that the probe trials, during which rats choose between the intermediate stimulus and either the positive or negative response options, allow us to track stimulus preferences across the length of the reversal phase (from initial performance, which is worse than chance, to an asymptote above chance). This approach revealed that quinpirole treatment selectively affects choice behaviour on the A- vs. $\mathrm{C}_{50 / 50}$ trials and that this effect is most apparent during later sessions of reversal learning. Our paradigm thus provides a novel method for studying stimulus perseveration (inhibiting the response at the previously rewarded stimulus, $\mathrm{A}^{-}$) and learned non-reward (approaching a previously non-rewarded stimulus, B+) in visual reversal learning, and builds upon previous work addressing these phenomena using e.g. three response options or replacement of one of the stimuli with a novel stimulus during the reversal phase (Alsiö et al. 2015; Clarke et al. 2007; Piantadosi et al. 2019); for a review, see (Nilsson et al. 2015). A selective blockade of learning from negative feedback, as reported here, is in agreement with previous findings of quinpirole-induced delays in overcoming perseverative responding at the previously correct response option in spatial reversal learning (Boulougouris et al. 2009). However, our data (see Fig. 2) strongly suggest that impaired learning from losses does not equate to poor performance preferentially during the early phase of visual discrimination reversal.

An alternative approach to studying learning from positive and negative feedback is used in the probabilistic selection task (Frank et al. 2004), where subjects initially learn the value of stimulus pairs without any probe trials, and new pairings are presented after learning has already taken place, in order to explore whether subjects have learned from positive or negative feedback. In the context of two-choice visual reversal learning ( $\mathrm{A}-\mathrm{vs} . \mathrm{B}+)$, this approach can be implemented as probe sessions with novel pairings $\left(\mathrm{A}-\mathrm{vs} . \mathrm{C}_{50 / 50}\right.$ and $\mathrm{B}+\mathrm{vs}$. 
$\mathrm{C}_{50 / 50}$ ) after a pre-defined number of trials or sessions (e.g. every five sessions for rodents). Whereas this would not have allowed us to follow the learning on a session-by-session basis, as the probe trials did in our design, the extent to which rats had learned from positive or negative feedback could have been evaluated in the drug-free state, separating the effects of drugs on choice from the effects of drugs on learning. In addition, although we here interpret choices on the probe trials as reflecting the extent to which the rats have learned about stimuli A and B during the standard trials, it is conceivable that the rats are solving the three different pairings (A vs. B; A vs. $\mathrm{C}_{50 / 50}$; $\mathrm{B}$ vs. $\mathrm{C}_{50 / 50}$ ) as separate problems. However, our paradigm addresses this by presenting probe trials less frequently than standard trials (one per eight trials versus six per eight trials). It therefore seems likely that learning primarily takes place during the standard A vs. B trials. Learning on probe trials is also impeded by the probabilistic nature of the feedback on these trials. The congruent effects of quinpirole at $0.25 \mathrm{mg} / \mathrm{kg}$ on negative probe trials in the VPVD task and $\alpha_{\text {loss }}$ in the PRL task supports the notion that performance on the probe trials reflects the estimated value of the positive and negative stimuli.

\section{Conclusion}

We used two different approaches and tasks to study how wins and losses shape choice behaviour in reversal learning in the rat. The first approach employed a behavioural probe during a standard visual discrimination reversal task, while the second involved computational modelling to define learning rates and other latent factors underlying choice behaviour in a PRL task. We report that the D2-like receptor agonist quinpirole has profound and remarkably similar effects across the two tasks: a complete blockade of learning from losses. These findings extend previous work in rodents, non-human primates, and humans, and is relevant for human disorders in which cognitive flexibility is impaired, such as schizophrenia and Parkinson's disease.

Acknowledgments This research was funded by a Wellcome Trust Senior Investigator award to TWR (104631/Z/14/Z). All experiments were conducted at the Behavioural and Clinical Neuroscience Institute, which was jointly funded by the Medical Research Council (MRC) and the Wellcome Trust. This research was also supported in part by the UK National Health Service (NHS) National Institute for Health Research (NIHR) Cambridge Biomedical Research Centre; the views expressed are those of the authors and not necessarily those of the NHS, the NIHR, or the Department of Health and Social Care. An MRC Clinical Research Infrastructure award supported part of this work. J.S.B. was supported by a $\mathrm{PhD}$ scholarship from the La Caixa Foundation, Spain, and a studentship from Boehringer Ingelheim Pharma GmbH, Germany. We thank Prof. T. J. Bussey for helpful discussions. We acknowledge the skilful technical assistance of A. Davison, V. Johnson and M. Selin in data collection. The experimental work was carried out under a Home Office Project Licence held by Dr. A. L. Milton.

\section{Compliance with ethical standards}

Conflict of interest T.W.R. discloses consultancy with Cambridge Cognition, Lundbeck, Mundipharma, and Unilever; he receives royalties from Cambridge Cognition and editorial honoraria from Springer Verlag and Elsevier. J.S.B. is supported by a studentship from Boehringer Ingelheim. J.A., B.U.P., S.R.O.N., T.C.C.P., A.R., J.M.P., L.L.C., J.W.D., R.N.C., and A.C.M. declare no conflicts of interest.

Open Access This article is distributed under the terms of the Creative Commons Attribution 4.0 International License (http:// creativecommons.org/licenses/by/4.0/), which permits unrestricted use, distribution, and reproduction in any medium, provided you give appropriate credit to the original author(s) and the source, provide a link to the Creative Commons license, and indicate if changes were made.

\section{References}

Alsiö J, Nilsson SR, Gastambide F, Wang RA, Dam SA, Mar AC, Tricklebank M, Robbins TW (2015) The role of 5-HT2C receptors in touchscreen visual reversal learning in the rat: a cross-site study. Psychopharmacology 232:4017-4031

Bari A, Theobald DE, Caprioli D, Mar AC, Aidoo-Micah A, Dalley JW, Robbins TW (2010) Serotonin modulates sensitivity to reward and negative feedback in a probabilistic reversal learning task in rats. Neuropsychopharmacology 35:1290-1301

Boulougouris V, Castane A, Robbins TW (2009) Dopamine D2/D3 receptor agonist quinpirole impairs spatial reversal learning in rats: investigation of D3 receptor involvement in persistent behavior. Psychopharmacology 202:611-620

Calabresi P, Gubellini P, Centonze D, Picconi B, Bernardi G, Chergui K, Svenningsson P, Fienberg AA, Greengard P (2000) Dopamine and cAMP-regulated phosphoprotein $32 \mathrm{kDa}$ controls both striatal longterm depression and long-term potentiation, opposing forms of synaptic plasticity. J Neurosci 20:8443-8451

Calaminus C, Hauber W (2008) Guidance of instrumental behavior under reversal conditions requires dopamine D1 and D2 receptor activation in the orbitofrontal cortex. Neuroscience 154:1195-1204

Cardinal RN, Aitken MR (2010) Whisker: a client-server high-performance multimedia research control system. Behav Res Methods 42:1059-1071

Chang CY, Esber GR, Marrero-Garcia Y, Yau HJ, Bonci A, Schoenbaum G (2016) Brief optogenetic inhibition of dopamine neurons mimics endogenous negative reward prediction errors. Nat Neurosci 19: $111-116$

Clarke HF, Walker SC, Dalley JW, Robbins TW, Roberts AC (2007) Cognitive inflexibility after prefrontal serotonin depletion is behaviorally and neurochemically specific. Cereb Cortex 17:18-27

Clarke HF, Cardinal RN, Rygula R, Hong YT, Fryer TD, Sawiak SJ, Ferrari V, Cockcroft G, Aigbirhio FI, Robbins TW, Roberts AC (2014) Orbitofrontal dopamine depletion upregulates caudate dopamine and alters behavior via changes in reinforcement sensitivity. $\mathrm{J}$ Neurosci 34:7663-7676

Clatworthy PL, Lewis SJ, Brichard L, Hong YT, Izquierdo D, Clark L, Cools R, Aigbirhio FI, Baron JC, Fryer TD, Robbins TW (2009) Dopamine release in dissociable striatal subregions predicts the different effects of oral methylphenidate on reversal learning and spatial working memory. J Neurosci 29:4690-4696

Cools R, Lewis SJ, Clark L, Barker RA, Robbins TW (2007) L-DOPA disrupts activity in the nucleus accumbens during reversal learning in Parkinson's disease. Neuropsychopharmacology 32:180-189 
Cox SM, Frank MJ, Larcher K, Fellows LK, Clark CA, Leyton M, Dagher A (2015) Striatal D1 and D2 signaling differentially predict learning from positive and negative outcomes. Neuroimage 109:95101

de Jong JW, Roelofs TJ, Mol FM, Hillen AE, Meijboom KE, Luijendijk MC, van der Eerden HA, Garner KM, Vanderschuren LJ, Adan RA (2015) Reducing ventral tegmental dopamine D2 receptor expression selectively boosts incentive motivation. Neuropsychopharmacology 40:2085-2095

den Ouden HE, Daw ND, Fernandez G, Elshout JA, Rijpkema M, Hoogman M, Franke B, Cools R (2013) Dissociable effects of dopamine and serotonin on reversal learning. Neuron 80:1090-1100

Eilam D, Szechtman H (1989) Biphasic effect of D-2 agonist quinpirole on locomotion and movements. Eur J Pharmacol 161:151-157

Eisenegger C, Naef M, Linssen A, Clark L, Gandamaneni PK, Muller U, Robbins TW (2014) Role of dopamine D2 receptors in human reinforcement learning. Neuropsychopharmacology 39:2366-2375

Ford CP (2014) The role of D2-autoreceptors in regulating dopamine neuron activity and transmission. Neuroscience 282:13-22

Frank MJ, Seeberger LC, O'Reilly RC (2004) By carrot or by stick: cognitive reinforcement learning in parkinsonism. Science 306 : 1940-1943

Frank MJ, Moustafa AA, Haughey HM, Curran T, Hutchison KE (2007) Genetic triple dissociation reveals multiple roles for dopamine in reinforcement learning. Proc Natl Acad Sci U S A 104:1631116316

Gerfen CR, Engber TM, Mahan LC, Susel Z, Chase TN, Monsma FJ Jr, Sibley DR (1990) D1 and D2 dopamine receptor-regulated gene expression of striatonigral and striatopallidal neurons. Science 250: $1429-1432$

Groman SM, Lee B, London ED, Mandelkern MA, James AS, Feiler K, Rivera R, Dahlbom M, Sossi V, Vandervoort E, Jentsch JD (2011) Dorsal striatal D2-like receptor availability covaries with sensitivity to positive reinforcement during discrimination learning. J Neurosci 31:7291-7299

Groman SM, James AS, Seu E, Tran S, Clark TA, Harpster SN, Crawford M, Burtner JL, Feiler K, Roth RH, Elsworth JD, London ED, Jentsch JD (2014) In the blink of an eye: relating positivefeedback sensitivity to striatal dopamine D2-like receptors through blink rate. J Neurosci 34:14443-14454

Gronau QF, Sarafoglou A, Matzke D, Ly A, Boehm U, Marsman M, Leslie DS, Forster JJ, Wagenmakers EJ, Steingroever H (2017a) A tutorial on bridge sampling. J Math Psychol 81:80-97

Gronau QF, Singmann H, Wagenmakers EJ (2017b) Bridgesampling: an $\mathrm{R}$ package for estimating normalizing constants. arXiv: 1710.08162

Hodge CW, Haraguchi M, Erickson H, Samson HH (1993) Ventral tegmental microinjections of quinpirole decrease ethanol and sucrosereinforced responding. Alcohol Clin Exp Res 17:370-375

Horst NK, Jupp B, Roberts AC, Robbins TW (2019) D2 receptors and cognitive flexibility in marmosets: tri-phasic dose-response effects of intra-striatal quinpirole on serial reversal performance. Neuropsychopharmacology 44:564-571

Izquierdo A, Wiedholz LM, Millstein RA, Yang RJ, Bussey TJ, Saksida LM, Holmes A (2006) Genetic and dopaminergic modulation of reversal learning in a touchscreen-based operant procedure for mice. Behav Brain Res 171:181-188

Klanker M, Sandberg T, Joosten R, Willuhn I, Feenstra M, Denys D (2015) Phasic dopamine release induced by positive feedback predicts individual differences in reversal learning. Neurobiol Learn Mem 125:135-145

Kravitz AV, Tye LD, Kreitzer AC (2012) Distinct roles for direct and indirect pathway striatal neurons in reinforcement. Nat Neurosci $15: 816-818$

Laughlin RE, Grant TL, Williams RW, Jentsch JD (2011) Genetic dissection of behavioral flexibility: reversal learning in mice. Biol Psychiatry 69:1109-1116
Lee B, Groman S, London ED, Jentsch JD (2007) Dopamine D2/D3 receptors play a specific role in the reversal of a learned visual discrimination in monkeys. Neuropsychopharmacology 32:21252134

Leeson VC, Robbins TW, Matheson E, Hutton SB, Ron MA, Barnes TR, Joyce EM (2009) Discrimination learning, reversal, and set-shifting in first-episode schizophrenia: stability over six years and specific associations with medication type and disorganization syndrome. Biol Psychiatry 66:586-593

Linden J, James AS, McDaniel C, Jentsch JD (2018) Dopamine D2 receptors in dopaminergic neurons modulate performance in a reversal learning task in mice. eNeuro 5:ENEURO.0229ENEU17.2018

Markou A, Salamone JD, Bussey TJ, Mar AC, Brunner D, Gilmour G, Balsam P (2013) Measuring reinforcement learning and motivation constructs in experimental animals: relevance to the negative symptoms of schizophrenia. Neurosci Biobehav Rev 37:2149-2165

Mehta MA, Swainson R, Ogilvie AD, Sahakian J, Robbins TW (2001) Improved short-term spatial memory but impaired reversal learning following the dopamine $\mathrm{D}(2)$ agonist bromocriptine in human volunteers. Psychopharmacology 159:10-20

Nilsson SR, Alsiö J, Somerville EM, Clifton PG (2015) The rat's not for turning: dissociating the psychological components of cognitive inflexibility. Neurosci Biobehav Rev 56:1-14

Pessiglione M, Seymour B, Flandin G, Dolan RJ, Frith CD (2006) Dopamine-dependent prediction errors underpin reward-seeking behaviour in humans. Nature 442:1042-1045

Phillips BU, Dewan S, Nilsson SRO, Robbins TW, Heath CJ, Saksida LM, Bussey TJ, Alsiö J (2018) Selective effects of 5-HT2C receptor modulation on performance of a novel valence-probe visual discrimination task and probabilistic reversal learning in mice. Psychopharmacology 235:2101-2111

Piantadosi PT, Lieberman AG, Pickens CL, Bergstrom HC, Holmes A (2019) A novel multichoice touchscreen paradigm for assessing cognitive flexibility in mice. Learn Mem 26:24-30

Schultz W (2013) Updating dopamine reward signals. Curr Opin Neurobiol 23:229-238

Smith AG, Neill JC, Costall B (1999) The dopamine D3/D2 receptor agonist 7-OH-DPAT induces cognitive impairment in the marmoset. Pharmacol Biochem Behav 63:201-211

Steinberg EE, Keiflin R, Boivin JR, Witten IB, Deisseroth K, Janak PH (2013) A causal link between prediction errors, dopamine neurons and learning. Nat Neurosci 16:966-973

Swainson R, Rogers RD, Sahakian BJ, Summers BA, Polkey CE, Robbins TW (2000) Probabilistic learning and reversal deficits in patients with Parkinson's disease or frontal or temporal lobe lesions: possible adverse effects of dopaminergic medication. Neuropsychologia 38:596-612

Verharen JPH, de Jong JW, Roelofs TJM, Huffels CFM, van Zessen R, Luijendijk MCM, Hamelink R, Willuhn I, den Ouden HEM, van der Plasse G, Adan RAH, Vanderschuren L (2018) A neuronal mechanism underlying decision-making deficits during hyperdopaminergic states. Nat Commun 9:731

Yapo C, Nair AG, Clement L, Castro LR, Hellgren Kotaleski J, Vincent P (2017) Detection of phasic dopamine by D1 and D2 striatal medium spiny neurons. J Physiol 595:7451-7475

Zalocusky KA, Ramakrishnan C, Lerner TN, Davidson TJ, Knutson B, Deisseroth K (2016) Nucleus accumbens D2R cells signal prior outcomes and control risky decision-making. Nature 531:642-646

Publisher's note Springer Nature remains neutral with regard to jurisdictional claims in published maps and institutional affiliations. 